\title{
Three-dimensional pathways of dust over the Sahara during summer 2011 as revealed by new Infrared Atmospheric Sounding Interferometer observations
}

\author{
Juan Cuesta ${ }^{1}$ | Cyrille Flamant ${ }^{2} \odot \mid$ Marco Gaetani $^{2,3}{ }^{\circledR}$ | Peter Knippertz ${ }^{4}$ | Andreas H. \\ Fink $^{4} \odot$ | Patrick Chazette ${ }^{5}$ | Maxim Eremenko ${ }^{1}$ | Gaëlle Dufour ${ }^{1}$ | Claudia Di Biagio ${ }^{1}$ | Paola \\ Formenti $^{1}$
}

${ }^{1}$ Laboratoire Interuniversitaire des Systèmes Atmosphériques, UMR CNRS 7583, Université Paris Est Créteil, Université de Paris, Créteil, France

${ }^{2}$ Laboratoire Atmosphères, Milieux, Observations Spatiales, UMR CNRS 8190, Sorbonne Université, Université Versailles Saint Quentin, Paris, France

${ }^{3}$ Department of Science, Technology and Society, Scuola Universitaria Superiore IUSS, Pavia, Italy

${ }^{4}$ Karlsruher Institut für Technologie, Institut für Meteorologie und Klimaforschung, Karlsruhe, Germany

${ }^{5}$ Laboratoire des Sciences du Climat et de l'Environnement, UMR CNRS 8212, Université Versailles Saint Quentin, Saclay, France

\section{Correspondence}

J. Cuesta, Laboratoire Interuniversitaire des Systèmes Atmosphériques, UMR CNRS 7583, Université Paris Est Créteil, Université de Paris, Créteil, France. Email: cuesta@lisa.u-pec.fr

\section{Funding information}

Agence Nationale de la Recherche, Grant/Award Number: ANR grant 2010 BLAN 606 01; Centre National d'Etudes Spatiales, Grant/Award Number: IASI project from TOSCA/CNES; Programme National de Télédétection Spatiale, Grant/Award Numbers: $\mathrm{n}^{\circ}$ PNTS-2013-05, project "SYNAEROZON"

\begin{abstract}
We present a new characterisation of the three-dimensional (3D) distribution of dust over the Sahara during summer, exemplified for June 2011. Our approach, called AEROIASI, is based on the innovative retrieval of vertical profiles of the dust extinction coefficient from daily cloud-free hyperspectral Infrared Atmospheric Sounder Interferometer (IASI) satellite observations. AEROIASI observations clearly agree with other widely used measurements (from lidar and radiometers). The 3D characterisation is focused on the dust maximum in June 2011, located in the central Sahara $\left(17-23^{\circ} \mathrm{N}, 1-7^{\circ} \mathrm{E}\right)$ and linked to the major atmospheric dynamical drivers associated with the West African Monsoon (WAM) system. AEROIASI shows the near-surface dust load to be dominated by five major emission events occurring every 3-4 days. These all occur when the study region is under the influence of northward bursts of the WAM and convection-related cold pools, likely associated with orographic forcing by the Aïr Mountains. During the earliest (June 10) and the dustiest (June 17) cases, northward advection of moisture over the hotspot is favoured by the superposition of cyclonic circulations related to an extratropical disturbance northwest of the Sahara and to the Saharan heat low over Mauritania, respectively. Convection over the hotspot also triggers wave-like disturbances that travel westwards. The three dustiest events are characterised by elongated dust fronts moving northwards, with a leading edge spanning 200-300 km horizontally and extending from the surface up to $2 \mathrm{~km}$ of altitude. Further south, the dust layer progressively elevates to $3.5 \mathrm{~km}$ along the slanted isentropes at the interface of the monsoon and the harmattan, increasingly losing contact with the ground. When northerlies blow over the study region, elevated dust layers at 3-5 km are observed, which are transported southwards within the Saharan air layer and westwards along the northern edge of the African easterly jet (after June 13).
\end{abstract}

\section{K E Y W O R D S}

cold pools, dust vertical profile, haboobs, West African monsoon bursts 


\section{1 | INTRODUCTION}

Desert dust plays a major role in the Earth system (e.g., Mahowald et al., 2001; Yoshioka et al., 2007; Knippertz and Stuut, 2014). In terms of mass concentration, it is one of the most abundant aerosol species in the atmosphere (e.g., Heald et al., 2014). The life cycle of desert dust and its numerous environmental impacts are closely related to its three-dimensional (3D) spatial distribution. Once uplifted from the surface over source regions, dust is transported to remote regions by atmospheric circulation (e.g., Yu et al., 2012; Guo et al., 2019; Liu et al., 2019). Depending on the altitudes at which it is transported, dust can have dramatically different impacts on the Earth's radiative budget (e.g., Haywood and Boucher, 2000; Meloni et al., 2005), atmospheric stability (e.g., Dunion and Velden, 2004; Jones et al., 2004) and cloud properties (e.g., Bangert et al., 2012), as well as chemical (e.g., Su et al., 2010) and biogeochemical (e.g., Mahowald et al., 2005) processes. When transported near the surface, dust causes poor air quality, low visibility and deposits on the ground (e.g., Xu et al., 1994; Prospero, 1999; Mahowald et al., 2007). Therefore, accurate knowledge of the 3D pathways of desert dust transport and the associated dynamical processes is fundamental for assessing its major impacts on the environment.

The Sahara is the world's largest source of dust aerosols. Dust emissions and transport within and beyond this region are driven by multiple dynamical mechanisms from micro to synoptic scales. Large amounts of dust are lifted after sunrise by strong near-surface winds associated with northeasterly dry harmattan flow enhanced by vertical mixing of the nocturnal low-level jet (LLJ) momentum down to the surface (e.g., Washington and Todd, 2005; Knippertz, 2008; Lothon et al., 2008). Near the surface, these winds encounter the southwesterly moist West African Monsoon (WAM) flow at the intertropical discontinuity (ITD; see the schematic in Figure 1), which is located over the Sahel from April to June (e.g., Bock et al., 2008; Couvreux et al., 2009; Guichard et al., 2009; Lélé and Lamb, 2010) and at the southern fringes of the Sahara in July and August (e.g., Sultan and Janicot, 2000, 2003; Cuesta et al., 2010). The winds at the leading edge of the WAM flow can act to uplift dust (e.g., Flamant et al., 2007; Bou Karam et al., 2008). Moreover, mesoscale convective systems (MCSs) travelling across the Sahel during summer often generate cold pools that propagate rapidly over long distances and lift substantial amounts of dust (Knippertz et al., 2007; Marsham et al., 2008; Flamant et al., 2009; Roberts and Knippertz, 2012). The cold-pool-related dust storms are also called haboobs and have a density-current-like appearance (e.g., Knippertz and Stuut, 2014). Orography is also known to trigger convection that leads to the generation of haboobs, as found over the Atlas Mountains (Knippertz et al., 2007), as well as the Hoggar and Aïr Mountains (Roberts and Knippertz, 2014). Other key dynamical actors of this region are the African easterly waves (AEWs) propagating along the African easterly jet (AEJ) within the $10-20^{\circ} \mathrm{N}$ latitudinal band (with typical periods of 3-5 days, detected at $700-850 \mathrm{hPa}$; see, e.g., Fink and Reiner, 2003). Knippertz and Todd (2010) showed that AEWs in concert with extratropical disturbances substantially contribute to the generation of a major dust hotspot over eastern Mauritania and northern Mali, through both emission and organisation of transport. Dust over this region is often uplifted by cold pools generated by convection associated with southerly moisture advection behind AEW troughs. Northerlies ahead of AEW troughs transport dust over the hotspot in the upper parts of the deep Saharan boundary layer (Chaboureau et al., 2016). The top of the boundary layer over the central Sahara may typically reach altitudes up to 5-6 km during summer (e.g., Cuesta et al., 2008, 2009).

Due to a lack of routine ground-based measurements over the Sahara, satellite observations play a central role in describing the spatial distribution of dust. At the daily scale, almost all satellite observations provide only two-dimensional (2D) information on dust distribution. This is done either in terms of the horizontal distribution of aerosol optical depth (AOD), typically derived by MODIS (Moderate Resolution Image Spectroradiometer; Remer et al., 2005; Sayer et al., 2013) and OMI (Ozone Monitoring Instrument, Torres et al., 2007), or vertical transects of the aerosol distribution along defined tracks measured by the space-borne lidars LITE (Lidar In-space Technology Experiment; Berthier et al., 2006) and CALIOP (Cloud-Aerosol Lidar with Orthogonal Polarization) on board the satellite CALIPSO (Cloud-Aerosol Lidar and Infrared Pathfinder Satellite Observations; Winker et al., 2007). However, tracking the evolution of the vertical dust distribution with a space-borne lidar alone at daily scales is difficult, since daytime or night-time transects are longitudinally spaced by large distances (around $2,000 \mathrm{~km}$ for CALIOP) in the midlatitudes and the tropics and the ground footprint is narrow (90 $\mathrm{m}$ in width for CALIOP).

Thermal infrared passive instruments such as the High-Resolution Infrared Radiation Sounder (HIRS-2) have been shown to be relevant for assessing both the vertical distribution and the optical thickness of aerosols, mainly in the stratosphere (Pierangelo et al., 2004). More recently, hyperspectral sounders have demonstrated the capability to derive the vertical distribution of desert dust. Daily observations of the top and mean heights of Saharan dust plumes have been derived, respectively, from AIRS (Atmospheric Infrared Sounder; DeSouza-Machado 


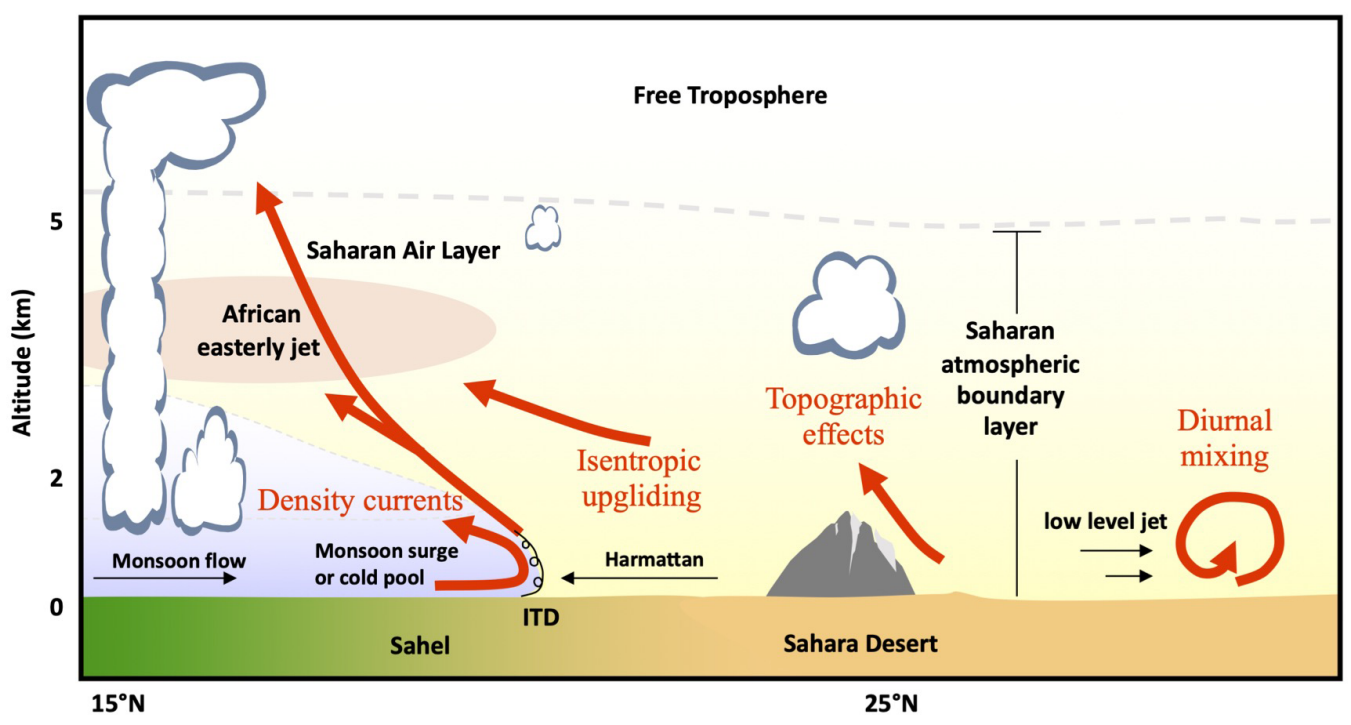

F I G U R E 1 Schematic of mechanisms (red arrows) that control the vertical distribution of dust near the intertropical discontinuity (ITD): isentropic upgliding, cold pools, monsoon surges, topographic effects (e.g., orography) and diurnal vertical mixing of momentum from low-level jets. Shading (yellow and light blue) indicates air mass origins (from the Saharan boundary layer or the Gulf of Guinea, respectively) and temperature. Mountains are found to both the north and the south of the ITD. Adapted from Cuesta et al. (2009) [Colour figure can be viewed at wileyonlinelibrary.com]

et al., 2010) and IASI (Infrared Atmospheric Sounding Interferometer; Kylling et al., 2018). Vertical profiles of dust load have been derived from IASI, initially over ocean with limited coverage over land (Vandenbussche et al., 2013) and more recently over both land and ocean (Cuesta et al., 2015; Callewaert et al., 2019). Moreover, IASI measurements have enabled the first 3D observations of both the vertical distribution and the horizontal structure of dust plumes with full coverage for cloud-free conditions, on a daily basis and over all surfaces (both land and ocean) using the so-called AEROIASI approach (Cuesta et al., 2015). AEROIASI uses the hyperspectral measurements of IASI to derive vertically resolved horizontal fields of the aerosol extinction coefficient at $10 \mu \mathrm{m}$ for cloud-free conditions. Previous studies using AEROIASI observations of the 3D distribution of dust were focused on East Asia (Cuesta et al., 2015) and the Middle East (Francis et al., 2019). For these studies, remarkable agreement between AEROIASI and CALIOP was found for several transects of vertical profiles of the major dust plumes.

In the present article, we use the AEROIASI approach to conduct the first observational study of the 3D distribution of dust over the Sahara and its link with the major atmospheric dynamical features over the region. We focus on the role of the WAM, cold pools, the Saharan heat low (SHL) and extratropical disturbances for enhancing dust emissions and modulating the 3D transport pathways of dust over the dustiest region in June 2011 (the latitude band from 17 to $23^{\circ} \mathrm{N}$ over the Sahara; Evan et al., 2015).
The month of June is one of the dustiest periods over the central Sahara (e.g., over Tamanrasset in southern Algeria; Cuesta et al., 2008; Klose et al., 2010) and is also the typical period of the onset of the WAM over the Sahel (see Figure 1; Sultan and Janicot, 2000), triggering the formation of numerous dust-rising MCSs (e.g., Marsham et al., 2008). We choose to analyse this month for the year 2011 due to the availability of surface-based measurements from the Fennec intensive field campaign over the central Sahara (Washington et al., 2012), which are used to support our study (sections 3.1 and 4.2).

First, we describe the AEROIASI approach (section 2.1), other datasets that are compared to it (sections 2.2-2.4) and the meteorological reanalysis used in the article (section 2.5). We then present a validation of the capability of AEROIASI to retrieve the 3D distribution of dust over the Sahara, as compared with CALIOP in the vertical, MODIS, OMI and SEVIRI (Spinning Enhanced Visible and Infrared Imager) in the horizontal and AERONET (Aerosol Robotic Network; Holben et al., 1998) stations in absolute estimates of column-integrated AOD (section 3). Afterwards, we detail a monthly analysis of the 3D distribution of dust over the Sahara and the associated dynamical features during June 2011 (section 4.1). Finally, we study the 3D distribution of dust when northward bursts of the WAM reach the central Sahara (section 4.2) and when it retreats south of this region (section 4.3), at daily scales and based on a composite view of several similar events. A summary is provided in section 5 . 


\section{2 | DATASETS}

\section{1 | AEROIASI over the Sahara}

The AEROIASI algorithm has been conceived to observe the 3D distribution of dust plumes for each overpass of IASI (Cuesta et al., 2015). These measurements offer global coverage twice daily at approximately 0930 and $2130 \mathrm{~h}$ local time, with pixels spaced by $25 \times 25 \mathrm{~km}^{2}$ at the nadir. The AEROIASI product is publicly available and can be provided on request. Here, we only use IASI measurements from the MetOp-A satellite, which was the only MetOp satellite operational in June 2011. For better comparison with sun photometer data, we use here AEROIASI retrievals for morning overpasses of IASI (although AEROIASI data is available for all overpasses; see, e.g., Cuesta et al., 2015; Kylling et al., 2018). The 3D distribution of dust is obtained from vertical profiles of the extinction coefficient at $10 \mu \mathrm{m}$ derived for each IASI pixel under cloud-free conditions and over all surfaces, even for the bright surfaces of the Saharan desert and for relatively low aerosol loads. Good agreement between dust extinction profiles derived from AEROIASI and the CALIOP lidar have been found, even for cases of moderate aerosol abundance (AOD 0.15). AOD is directly derived from vertical integration, and the mean aerosol layer height is estimated as the height below which the AOD is half that of the total column. The retrieval is based on a constrained-least-squares fit with explicit radiative transfer calculations, where the vertical distribution and abundance of dust are iteratively adjusted in order to best fit the IASI hyperspectral observations. Convergence is assured by auto-adaptive Tikhonov-Phillips-type constraints (Tikhonov, 1963), used for simultaneously adjusting the dust profile and surface temperature in order to offer good adaptability for different atmospheric and surface conditions. In order to limit the number of variables to be adjusted in the fitting procedure, surface emissivity is not modified during the retrievals. The information on the vertical dust distribution is provided by the spectral distribution of the measured infrared radiation over a relatively wide frequency range, which is mainly driven by thermal emission of the aerosol layers according to their temperatures and therefore their altitudes.

AEROIASI uses an a priori model of desert dust (including dust microphysical properties) and meteorological profiles provided as inputs to the line-by-line Karlsruhe Optimized and Precise Radiative transfer Algorithm (KOPRA; Stiller et al., 2000). KOPRA is used to simulate thermal infrared radiance spectra and the inversion module KOPRAFIT is used to compare them to those measured by IASI, for 12 spectral micro-windows in the atmospheric window between 8 and $12 \mu \mathrm{m}$. KOPRA accounts for light absorption, emission and single scattering by aerosols, using dust optical properties derived at each wavelength with a Mie code. Multiple scattering by dust particles is likely negligible in the thermal infrared (see the work by Cuesta et al., 2015 for more details). This is also the case for non-sphericity effects, except near the quartz resonant peak around $8.45 \mu \mathrm{m}$ (Legrand et al., 2014). We expect this effect to be limited for AEROIASI, since this approach only uses IASI measurements from a single spectral micro-window near $8.45 \mu \mathrm{m}$ (accounting for only $3 \%$ of the IASI channels used in the retrieval). The vertical grid is set between the surface and $12 \mathrm{~km}$ of altitude above mean sea level with $1 \mathrm{~km}$ increments. For each pixel, we use atmospheric temperature profiles and first guesses of surface temperatures and water vapor profiles from ECMWF (European Centre for Medium-Range Weather Forecasts) reanalyses. In order to minimise the spectral residuals, the method adjusts iteratively the radiative transfer inputs (mainly the aerosol vertical profile and the surface temperature) until convergence is reached (the maximum number of iterations is fixed to 10). The overall results of AEROIASI show that the degrees of freedom, or the number of independent pieces of information (determined following Rodgers, 2000), in the retrieval of dust profiles varies during the iterative procedure, a typical value of $\sim 1.5$ being used to determine the shape of the dust extinction profiles. According to sensitivity analyses (Cuesta et al., 2015), AEROIASI retrievals are not very sensitive to the dust model parameters or the a priori profiles of dust and water vapour (below 5\% for AOD and at most 14\% for the dust layer height), while the sensitivity is moderate with respect to the uncertainties of atmospheric and surface temperatures (typically below 15\%). Higher sensitivity (29\%) is only found for the retrieval of the AOD of elevated dust layers in the case of uncertainties of $\pm 2 \mathrm{~K}$ of the a priori surface temperature.

This article uses AEROIASI retrievals from version 2 of the algorithm, which mainly differs from that described by Cuesta et al. (2015) in the a priori desert dust model and the surface emissivity database. The desert dust model consists of values of the spectral complex refractive indices, a single-mode log-normal particle size distribution and an a priori vertical profile. The spectral complex refractive indices are taken from the spectroscopic analysis of field samples of Saharan dust performed by Di Biagio et al. (2014). We use a modal radius $(2.3 \mu \mathrm{m})$ and a modal width (standard deviation of 0.64 ) for the dust volume size distribution obtained by averaging volume effective radii and widths derived by AERONET measurements of the Zouerate station during June 2011 (from http://aeronet. gsfc.nasa.gov). This size distribution is consistent with the modal radius $(\sim 2.2 \mu \mathrm{m}$ in terms of volume) of the medium-sized mode of the size distribution measured by 
airborne in situ sensors for major dust events during June 2011 and over central western Sahara in the framework of the Fennec campaign (Ryder et al., 2013). Dust particles within this size range contribute in a major way to the total AOD in the thermal infrared and are transported over long distances. Fine dust particles (with radii smaller than $\sim 1 \mu \mathrm{m}$ ) account for less than $10 \%$ of the total AOD at $10 \mu \mathrm{m}$ (e.g., Cuesta et al., 2015). In the presence of very large, freshly uplifted dust particles, AEROIASI retrievals may be moderately biased. We can expect a negative bias of less than 5\% in the AOD at $10 \mu \mathrm{m}$ and a positive bias of less than $10 \%$ for the mean dust layer height for an increase of the effective radii of dust by 10\% (Cuesta et al., 2015).

A first guess of the dust vertical distribution (the same profile for all pixels and all days) is considered in the inversion as a background condition. This is obtained from an average of CALIOP extinction vertical profiles for dust over the Sahara during June 2011, scaled to particle concentration units in order to set an a priori AOD at $10 \mu \mathrm{m}$ of 0.03 .

The surface emissivity database is the same as that used for the intercomparison of satellite retrievals of dust height performed by Kylling et al. (2018), derived from a global monthly IASI-derived climatology over land (Paul et al., 2012) and a surface-temperature-dependent model over ocean (Newman et al., 2005). Using these new databases, we obtain lower spectral residuals with respect to IASI measurements than with the previous version, as well as higher adaptability for covering the tropical dust belt. Over this region, AEROIASI shows good performance for estimating the mean heights of dust layers (from the Atlantic to East Asia), corresponding to the lowest mean bias $(-0.045 \mathrm{~km})$ and the root-mean-square error $(1.029 \mathrm{~km})$ for a comparison with five other products (IASI- and GOME-2-based methods) with respect to CALIOP-derived geometric mean dust heights (Kylling et al., 2018).

\section{2 | Aerosol optical depth from the AERONET ground-based network}

In order to assess the quality of the AEROIASI dust observations over the Sahara, we perform comparisons similar to those shown by Cuesta et al. (2015) over East Asia. First, we compare AEROIASI retrievals of AOD with ground-based measurements from the AERONET sun photometer network. We consider 11 sites over the Sahara and the downwind Atlantic for the month of June 2011 (see the geographical location of the stations in Figure 2e; note that level 1.5 data are used for considering all these stations). For consistency, the comparison is made between AOD from AEROIASI retrieved at $10 \mu \mathrm{m}$ (mainly sensitivity to coarse particles) and extrapolated to $500 \mathrm{~nm}$ using an Angström exponent of 0.09 (derived from the climatological desert dust model, which accounts for absorptive differences in the spectral regions) and AERONET measurements of the so-called "coarse mode" AOD at $500 \mathrm{~nm}$ (available at http://aeronet.gsfc.nasa.gov; O'Neill et al., 2003). The criteria of spatiotemporal coincidence are $\pm 30 \mathrm{~min}$ and $\pm 1^{\circ}$ of latitude and longitude (thus considering several measurements for each item of the comparison and avoiding too much heterogeneity). In order to ensure a comparison in cloud-free conditions and to compare rather homogenous conditions, we only consider AERONET AOD observations with a temporal variability of less than 0.4 within $\pm 1 \mathrm{~h}$. Furthermore, we impose a minimum of three pixels of quality-checked AEROIASI retrievals and two AERONET measurements available per item of the comparison. Then, we compare the average of all observations within the coincidence criteria, from AEROIASI and AERONET, for each site and each day of the comparison.

\section{3 | Aerosol horizontal distribution from SEVIRI, MODIS and OMI}

To analyse the capability of AEROIASI to observe the horizontal distribution of Saharan dust, we compare it with other retrievals of dust AOD over the Sahara. We consider several satellite products based on different principles. Two different methods from geostationary observations of SEVIRI in the thermal infrared (with 3-km spatial resolution and available only over land) are used : (a) one based on a physical approach from Imperial College London (ICL) (Brindley and Russell, 2009; Banks and Brindley, 2013), here referred to "SEVIRI ICL", and (b) another based on a neural network, called here "SEVIRI NAS3" (North African Sand Storm Survey, http://nascube. univ-lille1.fr; Gonzalez and Briottet, 2017). We also compare them with: (c) MODIS combined Dark-Target (Remer et al., 2005) and Deep-Blue (Hsu et al., 2004; Sayer et al., 2013) retrievals from measurements from the TERRA satellite (collection 6.1, product MOD08_D3_v6.1) and (d) OMI data (product OMAERUVd_v003; Torres et al., 2007). The latter two products are provided at $1 \times 1^{\circ}$ resolution by the GIOVANNI portal (https://giovanni.gsfc. nasa.gov/). In the figures, the colour scale for AEROIASI is different from those of the other products (1 vs. 1.7). This accounts for the fact that AEROIASI is only sensitive to coarse particles (at $10 \mu \mathrm{m}$ ), whereas MODIS, OMI and AERONET retrieve total AOD at $500 \mathrm{~nm}$ and both SEVIRI products are scaled to visible total AOD for fine and coarse particle contributions. For temporal consistency with IASI measurements (around 0930 UTC for 


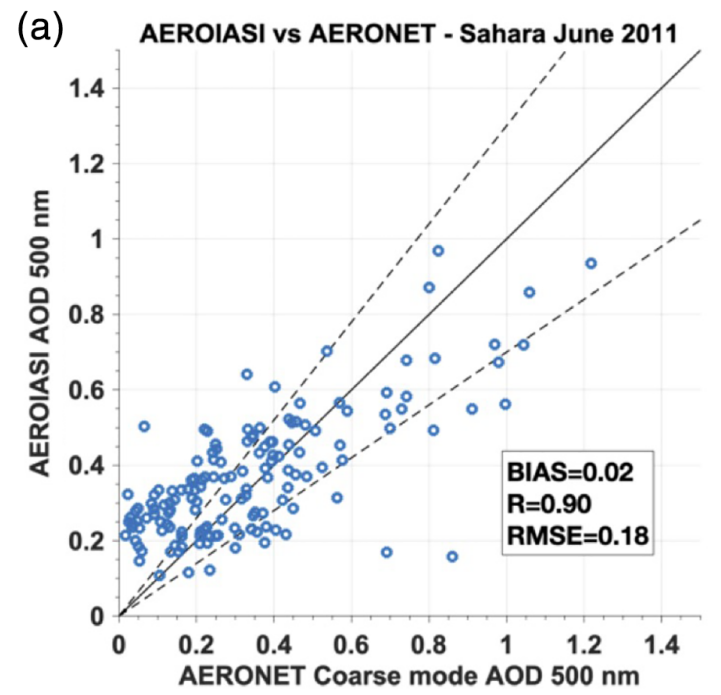

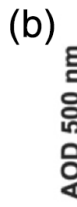

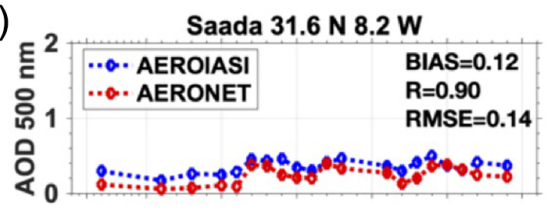

(c)

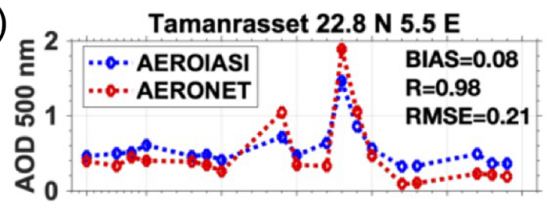

(d)

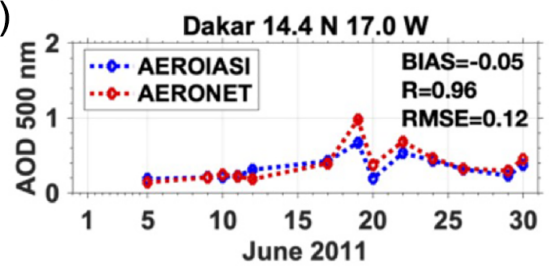

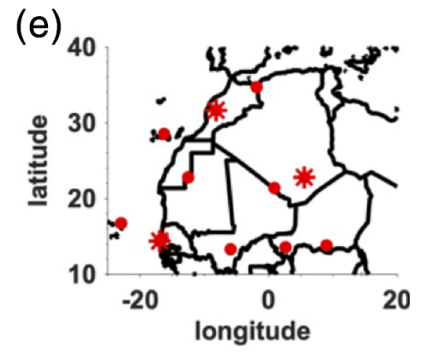

F I G U R E 2 Comparison of dust optical depth at $500 \mathrm{~nm}$ derived from AEROIASI and AERONET sun photometers over the Sahara during June 2011. We use aerosol optical depth (AOD) values extrapolated from the $10 \mu \mathrm{m}$ spectral band to $500 \mathrm{~nm}$ for AEROIASI and the coarse mode fraction for AERONET. (a) Scatterplot for all AOD values derived for the 11 AERONET stations (Agoufou, Banizoumbou, Bordj Badji Mokhtar, Capo Verde, Cinzana, Dakar, Oujda, Saada, Tamanrasset, Tenerife and Zouerate) indicated in red in the map of panel (e) with quality-checked retrievals from both AEROIASI and AERONET. Dashed black lines show the $\pm 30 \%$ with respect to the 1:1 line (solid black line). Time series of AOD for three stations (shown as asterisks in panel [e]): (b) Saada in northern Africa, (c) Tamanrasset in the central Sahara and (d) Dakar on the Atlantic coast southwest of the Sahara [Colour figure can be viewed at wileyonlinelibrary.com]

these days), we consider SEVIRI retrievals around 0930 UTC, MODIS retrievals from TERRA around 1030 UTC and AERONET measurements around 0930 UTC. OMI measurements are only available in the early afternoon (around 1330 UTC).

\section{4 | Aerosol vertical transects from CALIOP}

We use vertical transects of the aerosol extinction coefficient derived from CALIOP (Winker et al., 2007, 2009) over the Sahara to analyse the performance of AEROIASI in order to observe the vertical distribution of dust. To avoid unrealistically large particle extinction values near the surface, we derive dust extinction profiles from the inversion of CALIOP level 1 measurements (from http://www.icare.univ-lille1.fr), accounting for multiple scattering from particles. This is recommended by the CALIOP Algorithm Theoretical Basis Document (Young et al., 2008) for dense dust layers, although this has not yet been implemented in the official CALIOP level 2 products. As done previously over other regions(e.g., Cuesta et al., 2009, 2015), we use a classical inversion approach (Fernald et al., 1972; Fernald, 1984) considering a particle backscatter-to-extinction ratio of $0.024 \mathrm{sr}^{-1}$ typical for dust (Cattrall et al., 2005), modulated vertically by a multiple scattering coefficient (following Young et al., 2008).
As the time difference between the CALIOP and IASI measurements is significant (at least 3-4 hr), we need to roughly match these two observations in order to compare the same air masses. For this, we sample AEROIASI data considering the horizontal drift of the air masses observed by the CALIOP transect, estimated from wind fields from ERA5 reanalyses at the mean altitudes of the dust layers. Moreover, AEROIASI transects are obtained by averaging horizontally all available retrieved profiles within $\pm 1^{\circ}$ of latitude and longitude for the location of each CALIOP profile (a moving average). Before averaging, we interpolate AEROIASI profiles vertically every $100 \mathrm{~m}$ so as to be able to depict finer vertical resolution features.

\section{$2.5 \quad$ ERA5 meteorological reanalysis}

Meteorological conditions leading to dust uplift and transport over the Sahara are described in section 4 using ERA5 reanalyses (Hersbach and Dee, 2016) produced by the ECMWF. We use meteorological fields (from http:// climserv.ipsl.polytechnique.fr) with global coverage, a horizontal resolution of $0.25 \times 0.25^{\circ}, 137$ levels and a time step of $1 \mathrm{hr}$. Wind, equivalent potential temperature, potential temperature and geopotential fields are used to describe transport patterns and the locations of the WAM, the SHL, extratropical disturbances and wave-like perturbations. We delineate the ITD as the location of the change 
in wind direction between southwesterly monsoon winds and the northeasterly harmattan near the surface. For this, we combine two criteria often used in previous research by detecting (a) the change in the meridional wind direction (e.g., Hastenrath, 1990; Sultan and Janicot, 2003), which is located to the north and in the vicinity of (b) the $15^{\circ} \mathrm{C}$ isodrosotherm (dew point) at $2 \mathrm{~m}$ (e.g., Lélé and Lamb, 2010). According to Flamant et al. (2009), when the ITD is reached by a cold pool formed within the monsoon area, the cold pool leading edge becomes locally the ITD. In that case, we replace the previous criteria for detecting the ITD with the location of the leading edge of the dust front uplifted by the cold pool (using AEROIASI for detecting the dust plume). We depict the southerlies and northerlies associated with wave-like perturbations from wind fields at $850 \mathrm{hPa}$ filtered with a bandpass of 3-5 days (as often done elsewhere; e.g., Cuesta et al., 2009; Lavaysse et al., 2010).

\section{3 | VALIDATION OF THE AEROIASI APPROACH OVER THE SAHARA}

\section{1 | Dust optical depth}

Figure 2 shows good agreement of the AOD derived from AEROIASI and AERONET. Considering the total number of samples (147), the mean bias is low and positive $(+0.02)$, the linear correlation $R$ is high $(0.90)$ and the root-mean-square error (RMSE) between AODs is $\sim 0.18$ (Figure 2a). For individual sites, correlations may increase, and mean biases typically range from -0.1 to +0.1 (see examples in Figure 2b-d). The linear correlation for all stations over northern Africa is higher than that found for East Asia (0.79), presumably linked to the fact that the contribution of aerosol species other than desert dust is negligible over the Sahara during summer. This correlation is similar to that from other IASI retrievals of dust AOD over Saharan AERONET stations over a longer time period (Capelle et al., 2018) and is higher than that found over the tropical dust belt region (ranging from 0.45 to 0.8 ) by Popp et al. (2016).

The AOD time series for three stations at different latitudes and geographic settings (asterisks in Figure 2e) shows the ability of AEROIASI to observe the daily evolution of the AOD for desert dust over the Sahara (Figure 2b-d), both in the presence of dust events (timing and intensity, particularly for Tamanrasset and Dakar) and for background conditions of low dust load (see Saada station). Good AOD tracking ability by AEROIASI is also seen even for low AODs (e.g., at Saada, where a positive bias of about 0.1 is found). Two major dust events are clearly observed at Tamanrasset on June 14 and 18, 2011, in agreement with AERONET. Similar comparisons are found for other sites (not shown). The second AOD peak is associated with the major Saharan dust event investigated in detail in section 4.2.

Using these co-localised AERONET/AEROIASI datasets, we can also estimate a ratio of total AOD at $500 \mathrm{~nm}$ (sensitive to both fine and coarse particles) measured by sun photometers with respect to AEROIASI AOD retrievals at $10 \mu \mathrm{m}$ (sensitive to coarse dust particles). This ratio, which is on average 1.7, is used in section 3.2 as a scaling factor for the range of the colour bars for comparing AEROIASI AOD at $10 \mu \mathrm{m}$ with other measurements of total AOD at $500 \mathrm{~nm}$.

\section{2 | Dust horizontal distribution}

We compare the horizontal distribution of AOD from AEROIASI with those from SEVIRI, MODIS and OMI for two typical major Saharan dust events, such as the one described in detail in section 4.2 (June 17). We also compare these satellite data with ground-based measurements of AOD from AERONET sites, where available. Figures 3 and 4 highlight particularly good consistency between the horizontal distribution of dust observed by AEROIASI and those from the two SEVIRI products, but also with AERONET AOD measurements when available. These three satellite products provide a coherent picture of a large dust plume of $\sim 400 \times 400 \mathrm{~km}^{2}$ over the central Sahara (centred at $18^{\circ} \mathrm{N}, 2^{\circ} \mathrm{E}$ ) on June 17, 2011 (Figure 3a-c). It is transported northwestwards until it covers an elongated area of $\sim 1,000 \mathrm{~km}$ the following day (centred at $22^{\circ} \mathrm{N}, 2^{\circ} \mathrm{E}$, Figure $4 \mathrm{a}-\mathrm{c})$. For this large dust plume, AEROIASI and SEVIRI ICL retrieve similar AODs (respectively up to $\sim 3.2$ and $\sim 3.0$ on June 17 and $\sim 2.5$ and $\sim 2.0$ on June 18) and SEVIRI NAS3 retrieves moderately higher values ( $\sim 3.5$ on June 17 and $\sim 3.1$ on June 18). These values also agree reasonably well with AERONET measurements (Figures 3 and $4 \mathrm{f})$ at Bordj Badji Mokhtar $\left(21^{\circ} \mathrm{N}, 1^{\circ} \mathrm{E}\right.$, with AOD of $\sim 4$ on both days) but are significantly larger than at the mountainous Tamanrasset site on June $17\left(23^{\circ} \mathrm{N}, 5^{\circ} \mathrm{E}\right.$ and $1,320 \mathrm{~m}$ above sea level, with a total AOD of $\sim 0.5$ ), which might miss out dust in the lowest atmospheric layers.

The AEROIASI horizontal distribution of AOD is also fairly consistent with that shown by MODIS and OMI (Figures 3 and $4 \mathrm{~d}-\mathrm{e}$ ), but the latter two present lower values of AOD over the Sahara than AEROIASI, SEVIRI and AERONET. The large dust plume over the central Sahara is also depicted with high values of AOD by MODIS and OMI, but the MODIS AOD values are lower $(\sim 1)$ during both days and up to $\sim 1$ and $\sim 2$ for OMI on June 17 and 18, respectively. On June 17, the horizontal shape of the dust 
F I G U R E 3 Comparison of dust optical depth over northern Africa on June 17, 2011 derived by (a) AEROIASI, (b) SEVIRI using the Imperial College London (ICL) approach, (c) SEVIRI using the North African Sand Storm Survey (NAS3) method, (d) MODIS on board the TERRA satellite using the combined Dark Target/Deep Blue method, (e) OMI and (f) AERONET sun photometers. AEROIASI dust optical depth is estimated at $10 \mu \mathrm{m}$ and other approaches at $500 \mathrm{~nm}$.

The difference in the colour scale (AEROIASI up to 1 and other products up to 1.7) accounts for the differences in wavelength.

AERONET measurements are presented in small circles for coarse mode AOD, surrounded by larger circles showing all AOD. The time of the measurement is shown in the title of each panel. The dashed magenta line in panel (a) is the CALIOP track of Figure $5 a, b$ [Colour figure can be viewed at wileyonlinelibrary.com]
17 June 2011
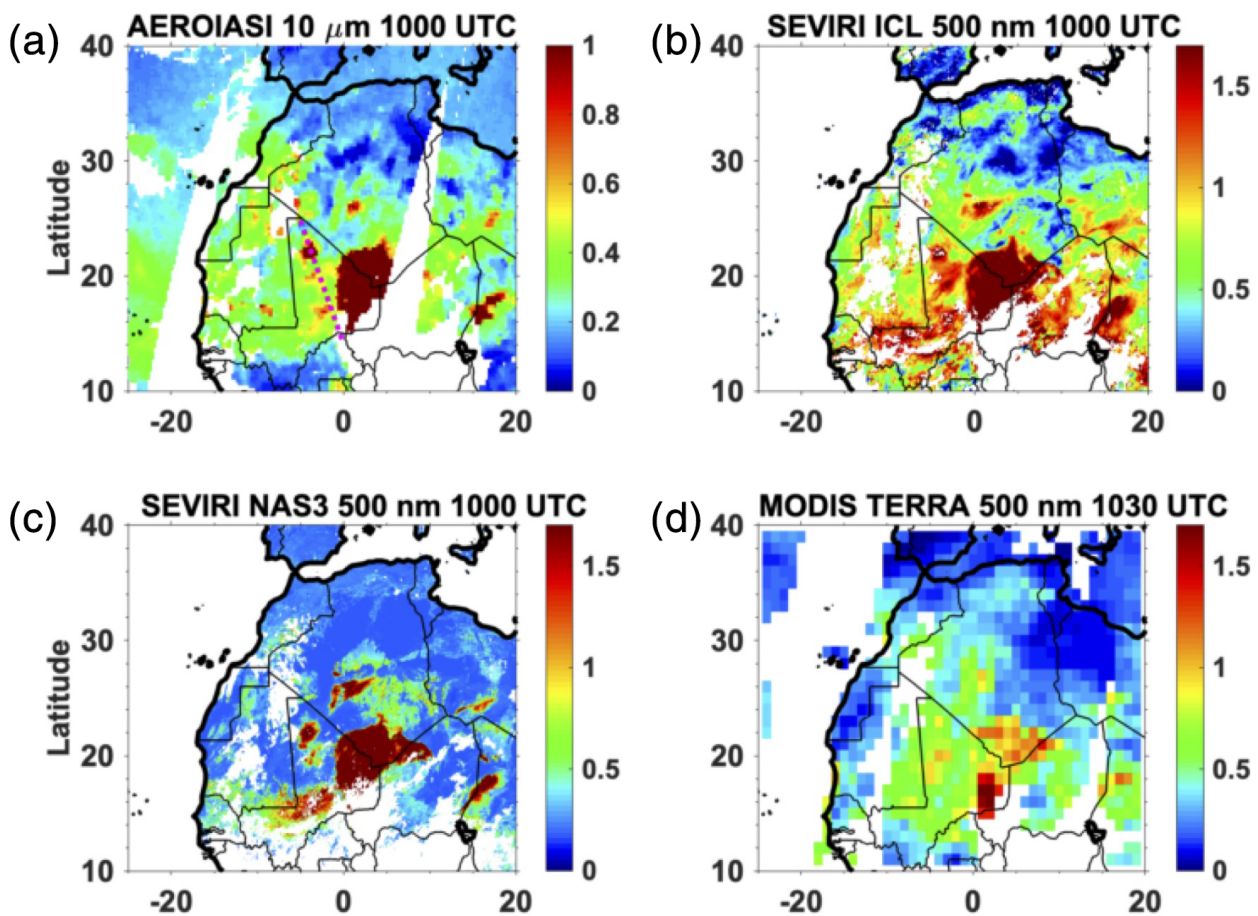

1.5
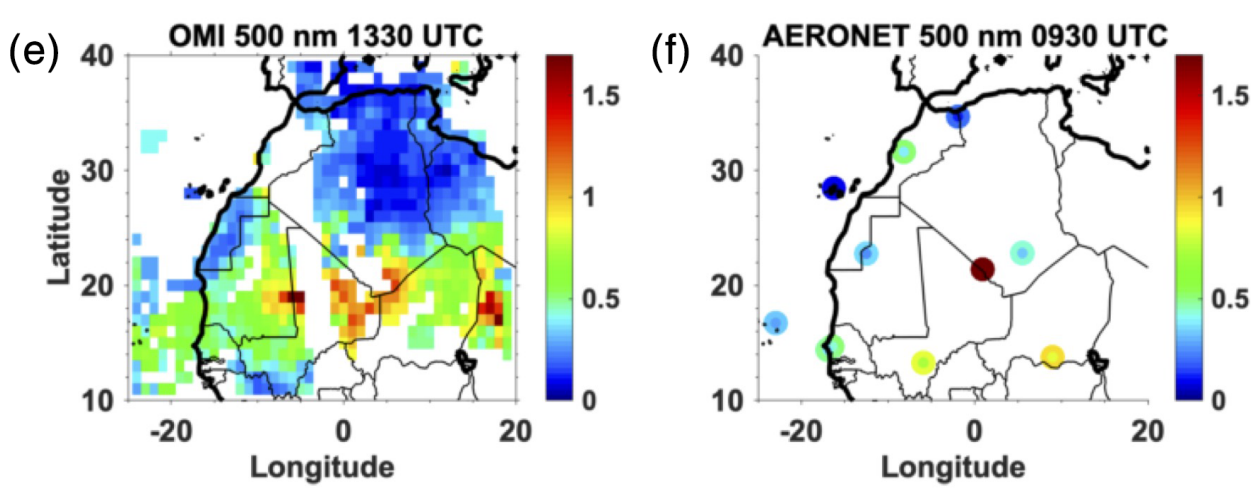

plume observed with these instruments differs markedly from those of AEROIASI and SEVIRI. Greater consistency between the five satellite products is found with respect to the plume shape on June 18.

Smaller dust plumes with high AOD (over $~ 1.5$ ) are also retrieved by AEROIASI and the SEVIRI products with a similar horizontal structure, for example, north $\left(25^{\circ} \mathrm{N}\right.$, $\left.2^{\circ} \mathrm{E}\right)$ and northwest $\left(22^{\circ} \mathrm{N}, 4^{\circ} \mathrm{W}\right)$ of the large dust plume over the central Sahara on June 17 (Figure 3a-c). The MODIS dataset does not depict these two smaller dust plumes (with AOD $\sim 0.8$ ) as clearly as the other satellite datasets. OMI shows high values of AOD (1.7) only near $20^{\circ} \mathrm{N}, 4^{\circ} \mathrm{W}$. All five satellite datasets show a dust plume southeast of the Sahara on June $17\left(15^{\circ} \mathrm{N}, 15^{\circ} \mathrm{E}\right)$ and southwest of the Sahara on June $18\left(20^{\circ} \mathrm{N}, 10^{\circ} \mathrm{W}\right)$. Only SEVIRI ICL shows dense dust plumes south of $15^{\circ} \mathrm{N}$, which might be a spurious effect of unscreened clouds. Similar background values of AOD extending over most of the Sahara are retrieved by AEROIASI, SEVIRI ICL, MODIS and OMI, as well as AERONET data ranging from 0.3 to 0.5 (see the complementary results of Banks et al., 2013 comparing SEVIRI ICL, MODIS and AERONET). The SEVIRI NAS3 dataset, however, shows lower background AOD values $(\sim 0.2)$.

In summary, these comparisons show an overall consistency of AEROIASI satellite observations of dust AOD with respect to other validated and widely used space-borne sensors (SEVIRI, MODIS and OMI) and ground-based observations (AERONET).

\section{3 | Dust vertical distribution}

Comparisons between vertical transects of the dust extinction coefficient from AEROIASI and CALIOP (at $10 \mu \mathrm{m}$ and $532 \mathrm{~nm}$, respectively) are illustrated in Figure 5 for 


\section{June 2011}

(a)

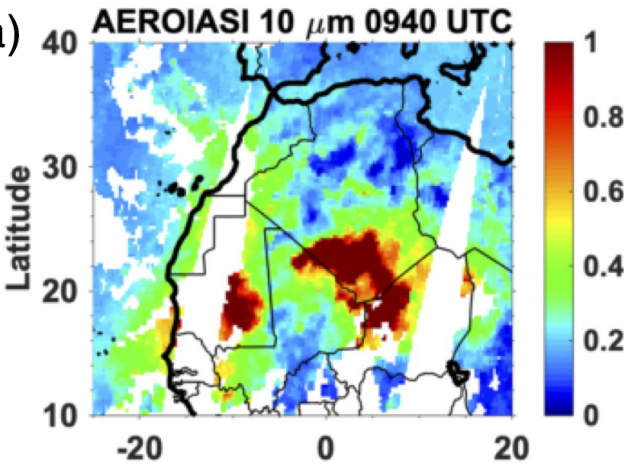

(c)
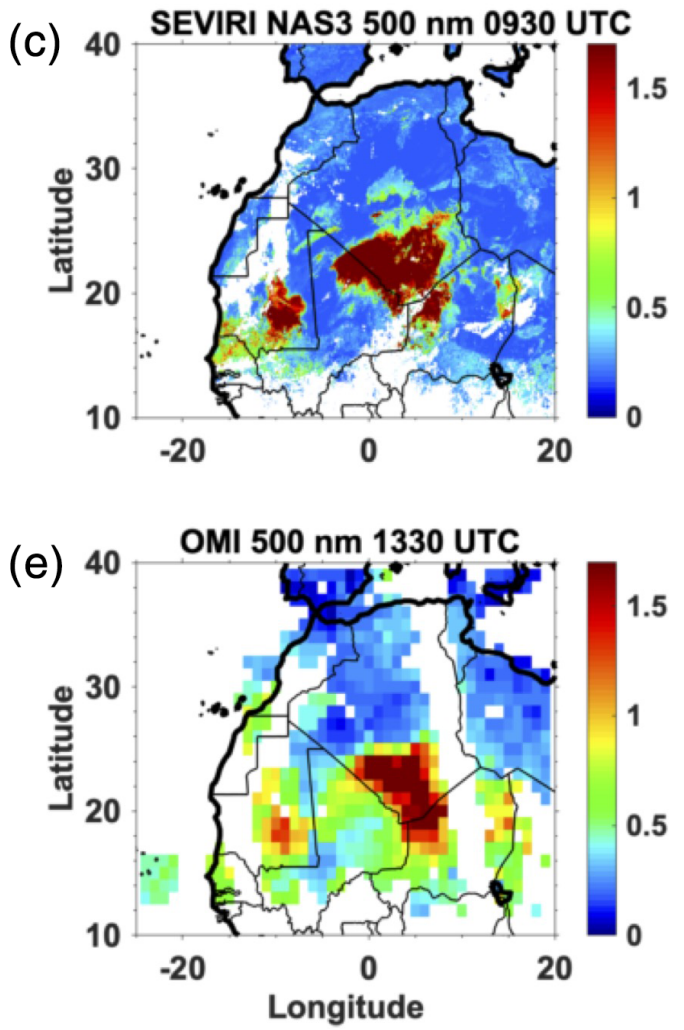

(b)

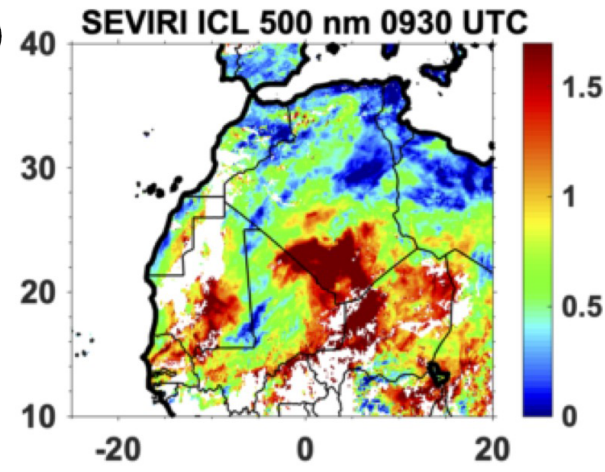

(d)

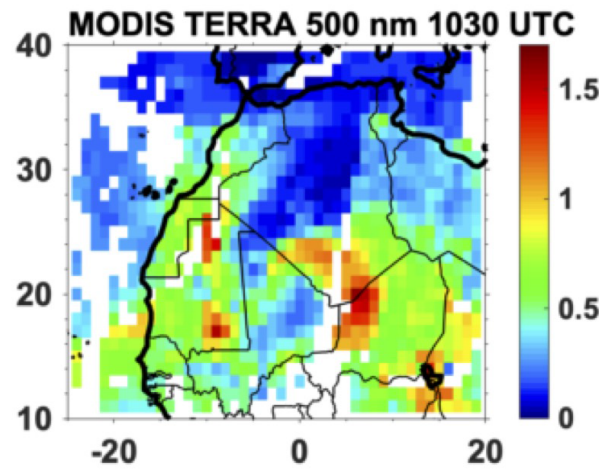

(f)

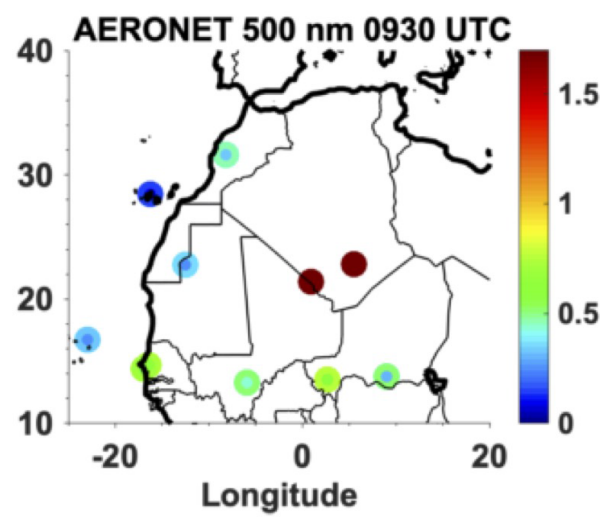

F I G U R E 4 As Figure 3, but for June 18, 2011 [Colour figure can be viewed at wileyonlinelibrary.com]

two cases on June 17 and 19, 2011, respectively (no coincidences are available for June 18). These transects sample dense dust plumes during the dust outbreak over the central Sahara analysed in detail in section 4.2. The overall vertical distributions depicted by these two datasets, AEROIASI and CALIOP, agree remarkably well. The same dust layers with similar vertical extents are found in both measurements. On June 17, both active and passive observations show very clearly the same two dust plumes reaching the surface, at $15-17^{\circ} \mathrm{N}$ and $21-23^{\circ} \mathrm{N}$, respectively, extending up to $\sim 5-6 \mathrm{~km}$ and $\sim 2.5 \mathrm{~km}$ of altitude, and an elevated dust layer from $\sim 3.5$ to $\sim 5.5 \mathrm{~km}$ at $18-21^{\circ} \mathrm{N}$. The near-surface dust layers correspond to dust uplifted by strong winds along the leading edge of a cold pool $\left(15-17^{\circ} \mathrm{N}\right.$, detected using SEVIRI AOD measurements) and enhanced harmattan winds $\left(21-23^{\circ} \mathrm{N}\right)$, respectively. The elevated dust is located within a residual atmospheric boundary layer and corresponds to long-range transport from eastern sources (see section 4 for more detail). On June 19, both datasets also agree in the depiction of a very dense dust layer extending from around $1-5 \mathrm{~km}$ of altitude at $20-22^{\circ} \mathrm{N}$, resulting from dust uplifted by a cold pool and an elevated dust layer around $4-5 \mathrm{~km}$ of altitude reaching northward to $24.5^{\circ} \mathrm{N}$. Some differences are also found, such as higher extinction values retrieved by AEROIASI for the dust layers at $15-17^{\circ} \mathrm{N}$ and an additional layer north of $25^{\circ} \mathrm{N}$ on June 17. These could be linked to the temporal difference between 
CALIOP Aerosol extinction profiles $532 \mathrm{~nm}$
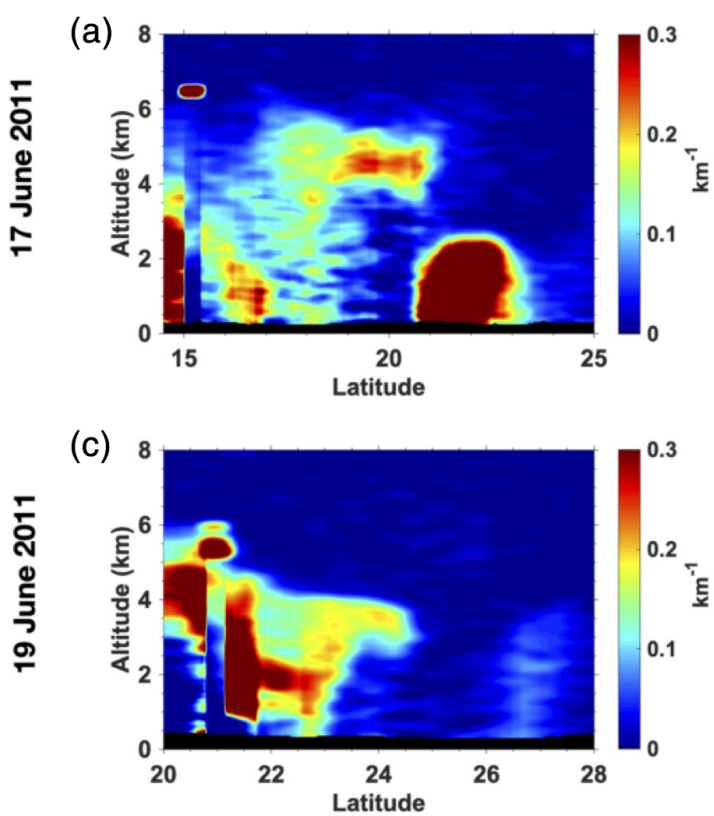

AEORIASI Dust extinction profiles $10 \mu \mathrm{m}$

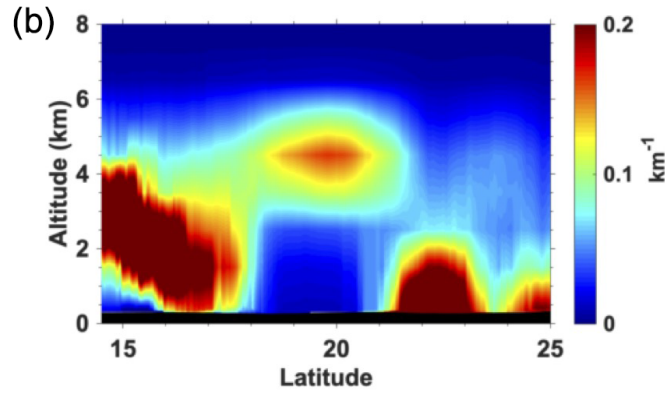

(d)

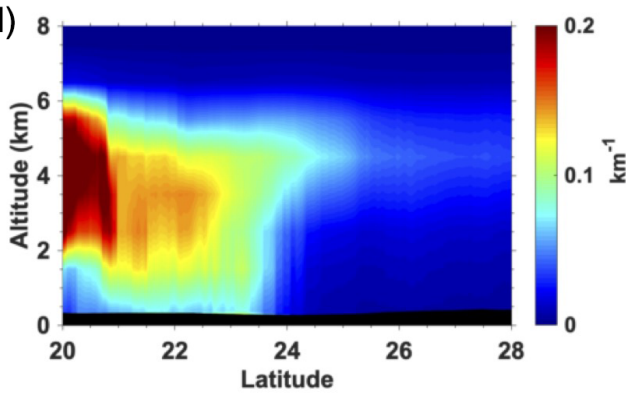

F I G U R E 5 Vertical transects of aerosol extinction derived from (a, c) CALIOP at $532 \mathrm{~nm}$ around 1300 UTC and (b, d) AEROIASI at $10 \mu \mathrm{m}$ around $1000 \mathrm{UTC}$, respectively for (a, b) June 17, 2011 and (c, d) June 19, 2011. For CALIOP, aerosol extinction is derived from attenuated backscatter measurements using a standard inversion approach and accounting for multiple scattering. For co-localisation between AEROIASI and CALIOP, AEROIASI data are sampled at the location of the air masses observed by CALIOP approximately $3 \mathrm{hr}$ later. High values of extinction at $6.5 \mathrm{~km}$ and $15^{\circ} \mathrm{N}$ (a) and $5.5 \mathrm{~km}$ and $21^{\circ} \mathrm{N}$ (c) of altitude for CALIOP are associated with the presence of clouds [Colour figure can be viewed at wileyonlinelibrary.com]

the two datasets or uncertainties in the retrievals (e.g., cloud screening, the choice of backscatter-to-extinction ratio for CALIOP, or dust and surface properties for AEROIASI). Overall, the agreement with CALIPSO observations illustrates the good capacity of AEROIASI to depict the vertical distribution of dust plumes and their horizontal extent along the CALIOP track.

\section{I IMPACT OF WAM DYNAMICAL FEATURES ON THE 3D DISTRIBUTION OF DUST}

In this section, we investigate the role of cold air intrusions associated with the WAM or deep convection-driven cold pools as direct or indirect drivers of emissions and 3D transport of dust plumes over the central Sahara. This analysis is based on the new observations of AEROIASI of the 3D dust distribution and ERA5 reanalysis data.

\section{1 | Daily evolution of dust over the central Sahara during June 2011}

According to AEROIASI observations averaged over June 2011 (Figure 6a), the largest values of AOD are clearly found over the point of the triple frontier of Algeria, Nigeria and Mali (i.e., the region $17-23^{\circ} \mathrm{N}, 1-7^{\circ} \mathrm{E}$ ). This area is a known large and systematic source of dust during summer (previously identified with SEVIRI data; Schepanski et al., 2007; Cuesta et al., 2008; Kocha et al., 2013). This hotspot is surrounded by the Aïr, Hoggar and Adrar des Ifoghas Mountains respectively east, north and west of it (see Figure 6c). According to 3D observations from AEROIASI (Figure 6b), dust over this area extends vertically from the surface up to $5 \mathrm{~km}$ of altitude, with the highest abundance from 3 to $5 \mathrm{~km}$ and some localised maxima at the surface, probably linked to frequent dust emission. While the monthly average AOD at $10 \mu \mathrm{m}$ for this region is higher than $\sim 0.5$, moderate values of $\sim 0.3$ are observed across the whole of northern Africa in the latitude band from 13 to $32^{\circ} \mathrm{N}$. Over the Atlantic, dust is mainly transported in the latitude band from 10 to $24^{\circ} \mathrm{N}$ as shown by higher AODs and winds from the continent. On the contrary, north of $24^{\circ} \mathrm{N}$ the flow is from the Atlantic to the continent.

In the following, we focus on the dynamical features associated with the particularly high dust amounts over $17-23^{\circ} \mathrm{N}, 1-7^{\circ} \mathrm{E}$, which is analysed in terms of the daily evolution of dust and meteorological variables presented as time/longitude Hovmöller graphs (Hovmöller, 1949) in Figures 7 and 8 and time series centred over this region 

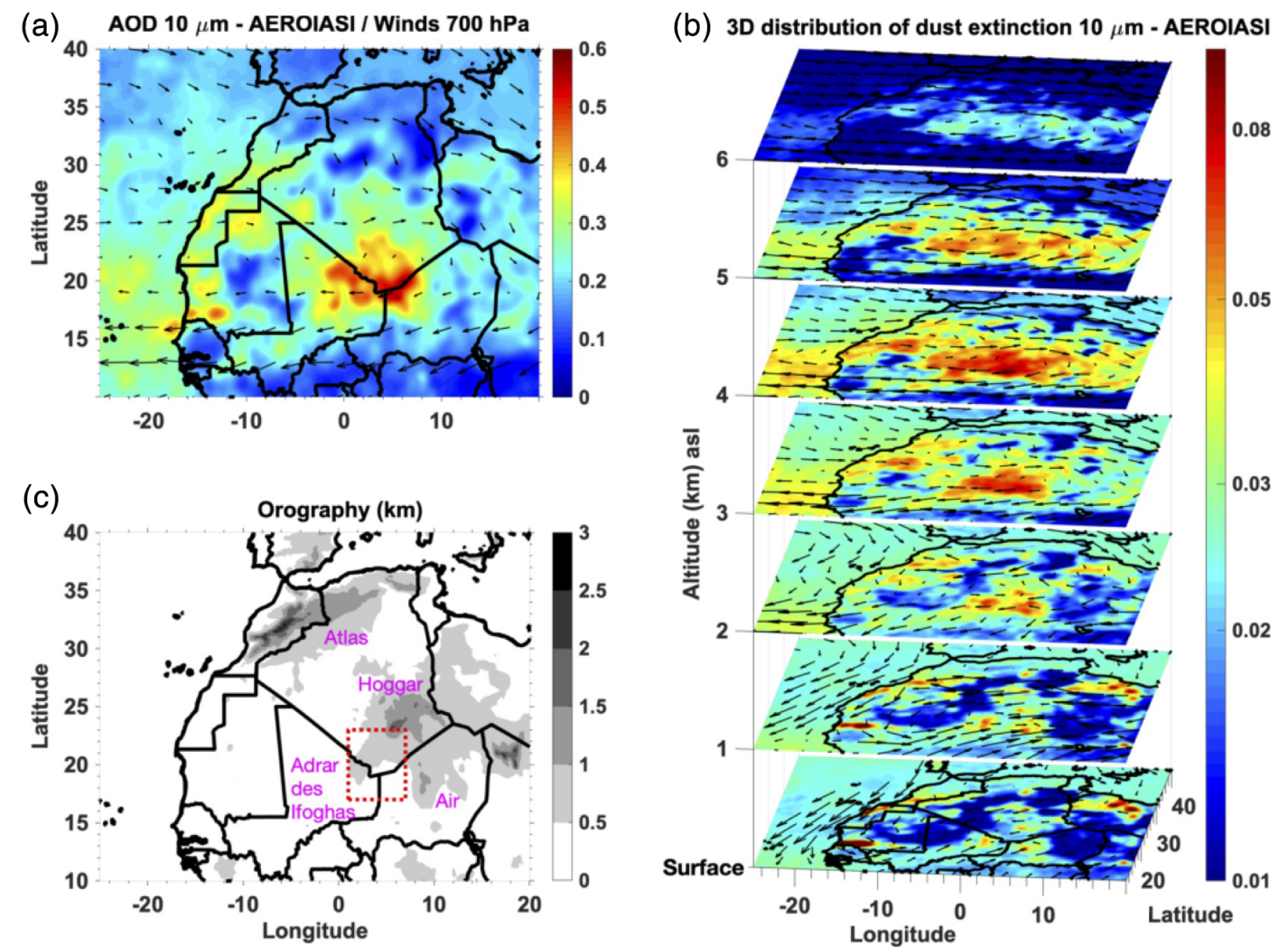

F I G U R E 6 Monthly average of AEROIASI observations over northern Africa in June 2011: (a) AOD at $10 \mu \mathrm{m}$ and (b) 3D distribution of dust in terms of extinction coefficient at $10 \mu \mathrm{m}$. Wind reanalysis fields from ERA5 at $700 \mathrm{hPa}$ and at each level of the of the graph are overlaid on panels (a) and (b) respectively. Panel (c) shows the orography of northern Africa and the dust hotspot in the central Sahara observed in June 2011 (red dashed area) [Colour figure can be viewed at wileyonlinelibrary.com]

in Figure 9. An original aspect of this Hovmöller analysis is that we distinguish between dust extinction at different altitudes for the first time, based on the new 3D observations of AEROIASI.

For the latitude band with maximum dust load $\left(17-23^{\circ} \mathrm{N}\right)$, we observe different time/longitude evolutions of dust extinction depending on altitude (Figure 7c,f,i). At the surface, dust events mainly occur in two longitudinal bands over the central $\left(1^{\circ} \mathrm{W}-9^{\circ} \mathrm{E}\right)$ and western $\left(18-10^{\circ} \mathrm{W}\right)$ Sahara. High amounts of dust do not show the slanted continuous pattern in time and longitude generally associated with transport. On the contrary, they are temporally distinct events, consistent with the behaviour of dust emissions. High surface dust loads are mostly observed in concomitance with high surface wind speeds (greater than approximately $5 \mathrm{~m} \cdot \mathrm{s}^{-1}$ ), in either the meridional, zonal or both directions. The two earliest peaks of surface dust (June 5 and 10) are concomitant with strong westerlies over the hotspot, probably associated with extratropical disturbances occurring northwest of Morocco (see the upper troughs in geopotential height anomalies at $300 \mathrm{hPa}$ over $35-40^{\circ} \mathrm{N}$ in Figure 8a). These disturbances are also seen above $2 \mathrm{~km}$ at $17-23^{\circ} \mathrm{N}$ as westerlies (strongest on June 5 and 12; Figure 7b,e) and southerlies moving westwards (at $1-7^{\circ} \mathrm{E}$ on June 5; Figure $7 \mathrm{a}, \mathrm{d}$ ). The following four events of abundant surface dust (June 13-14, $17,19-20$ and 23 ) are triggered by the periodical occurrence of southerlies propagating westwards (along the green dashed lines in Figure 7g). These surface winds are coherently preceded by easterlies and followed by westerlies (Figure 7h), therefore suggesting cyclonic vortices (coincident with troughs of negative geopotential height anomalies, not shown). By manually tracking these four successive propagating features (also seen as southerlies at 2-3 km; Figure 7d) we estimate a propagation speed $c$ of 4-6 $\mathrm{m} \cdot \mathrm{s}^{-1}$, periods $T$ of 3-5 days and wavelengths $\lambda$ of $1,500-2,300 \mathrm{~km}$. As they are first observed at the longitudes of the hotspot $\left(1-7^{\circ} \mathrm{E}\right.$ in all four cases), they are likely perturbations generated as a consequence of the convective activity over this area (see details at the end of this section). These wind structures have a wave-like behaviour, as they fulfil the wave relation (i.e., $c=\lambda / T$ ), have the same wave period as AEWs and also propagate along the AEJ (seen as easterlies above $2 \mathrm{~km}$ of altitude after June 13; Figure 7b,e). However, they are somewhat untypical. AEWs usually propagate faster $\left(\sim 8 \mathrm{~m} \cdot \mathrm{s}^{-1}\right.$, e.g., Lafore et al., 2011), have 

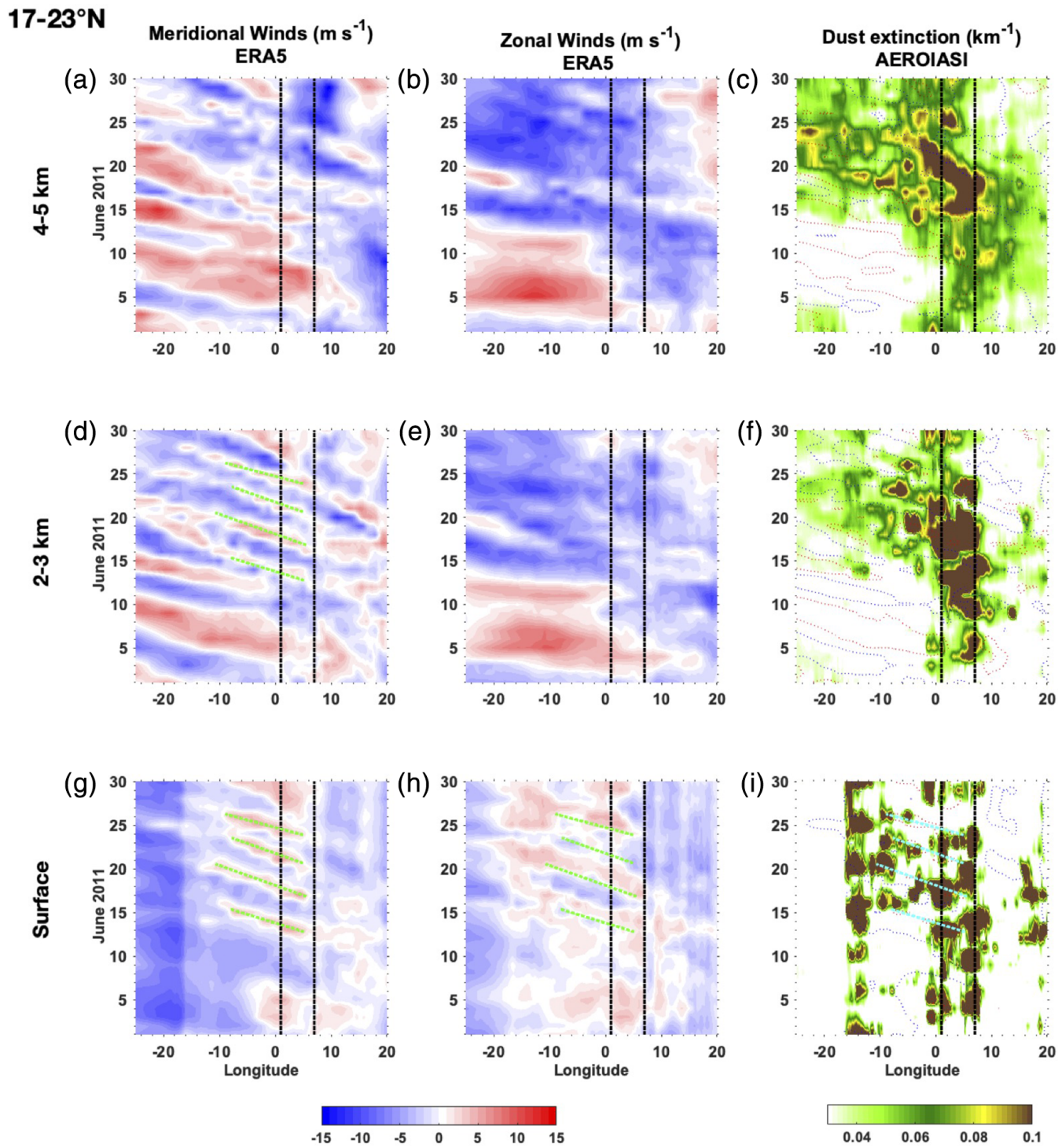

F I G U R E 7 Hovmöller graphs of daily evolutions during June 2011 of (a, d, g) meridional and (b, e, h) zonal wind from ERA5 and (c, f, i) dust extinction observations at $10 \mu \mathrm{m}$ derived from AEROIASI, averaged over the latitude band $17-23^{\circ} \mathrm{N}$ (the latitude of the monthly AOD maximum). Different altitudes are shown: $10 \mathrm{~m}$ for wind and 0-1 km for dust (lower panels), 2-3 km of altitude (middle panels) and 4-5 km of altitude (middle panels). In the right panels, dashed contours of meridional winds of $\pm 3 \mathrm{~m} \cdot \mathrm{s}^{-1}$ (red/blue) are overlaid on dust extinction fields. Gaps in the AEROIASI time series for each geographical location are filled by interpolation between available data. Dotted black lines indicate the longitudinal band of the dust hotspot $\left(1-7^{\circ} \mathrm{E}\right)$ and dotted green lines depict the four events of westward propagating southerlies at the surface level initiating over the hotspot (the same lines are shown in panels $\mathrm{d}, \mathrm{h}$ and $\mathrm{i}$, in cyan for this last case) [Colour figure can be viewed at wileyonlinelibrary.com]

longer wavelengths $(2,000-4,000 \mathrm{~km})$, are more intense at higher altitudes $(2-3 \mathrm{~km}$ or $850-700 \mathrm{hPa})$ and originate at a more easterly location (east of $20^{\circ} \mathrm{E}$ ) than the waves observed over the hotspot from June 13 to 23 .

Elevated layers of high dust amounts are continuously observed over the central Sahara $\left(1^{\circ} \mathrm{W}-9^{\circ} \mathrm{E}\right)$ without longitudinal transport until June 13 (both at $2-3 \mathrm{~km}$ and 4-5 km of altitude, shown respectively in Figure 7f,c). After this day, the dust load above $2 \mathrm{~km}$ significantly increases and is advected westwards out to $20^{\circ} \mathrm{W}$. Easterly transport is clearly linked to a change in the zonal wind regime from westerlies at the beginning of the month (associated with extratropical disturbances northwest of Morocco) to sustained easterlies after June 13, once the northern edge of the AEJ reaches this latitude band (see Figure $7 \mathrm{~b}, \mathrm{e}$ ). At $2-3 \mathrm{~km}$ of altitude, the highest dust loads are mainly observed over the central Sahara $\left(1^{\circ} \mathrm{W}-9^{\circ} \mathrm{E}\right)$ and only some moderate dust amounts are transported westwards, whereas at $4-5 \mathrm{~km}$ the densest dust layers are observed during the period of transport from the central Sahara to the western Sahara (shown respectively in Figure 7f,c). 
$35-40^{\circ} \mathrm{N}$

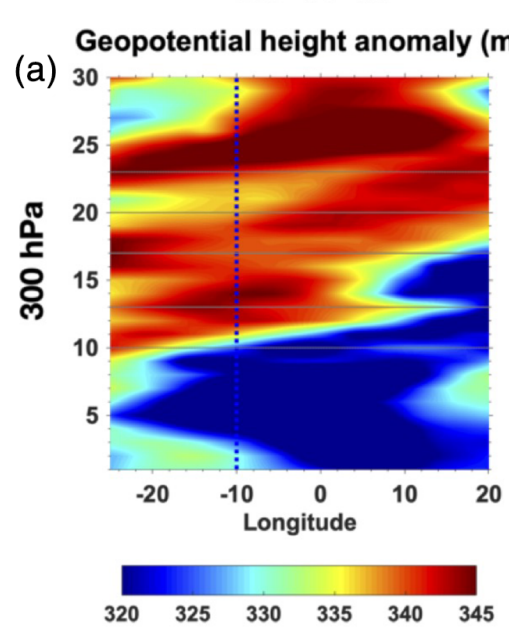

$20-25^{\circ} \mathrm{N}$

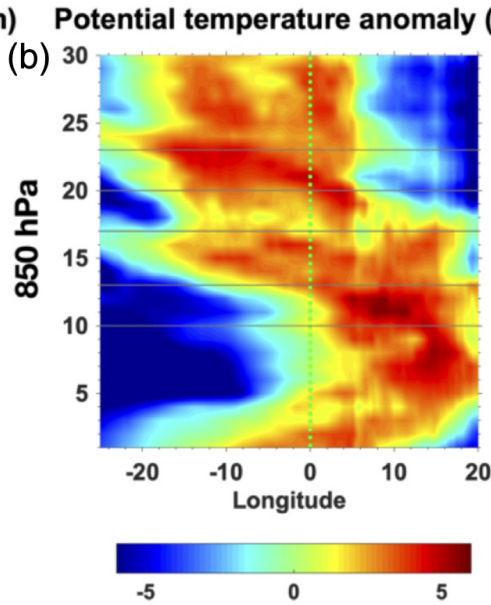

$17-23^{\circ} \mathrm{N}$

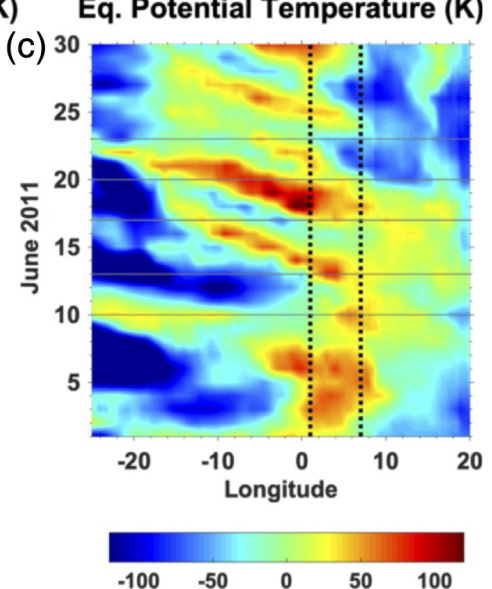

F I G U R E 8 Hovmöller graphs of daily evolutions during June 2011 of: (a) geopotential height anomalies at $300 \mathrm{hPa}$ for depicting the occurrence of extratropical (at $35-40^{\circ} \mathrm{N}$ ) disturbances affecting the atmospheric circulation over the Sahara (particularly when located west of $10^{\circ} \mathrm{W}$; blue dotted line), (b) potential temperature anomalies at $850 \mathrm{hPa}$ and over $20-25^{\circ} \mathrm{N}$ used as a proxy to assess the longitudinal position of the Saharan heat low (SHL) and its intensity and (c) equivalent potential temperature at $850 \mathrm{hPa}$ over the latitude of the hotspot $\left(17-23^{\circ} \mathrm{N}\right)$ to indicate the northward burst of the West African Monsoon (WAM; higher values correspond to monsoonal air masses). When the SHL position shifts west of $0^{\circ} \mathrm{E}$ (green dotted line), the associated cyclonic circulation favours the northward excursions of the WAM over the hotspot. Grey horizontal lines indicate the days of AOD peaks at the hotspot [Colour figure can be viewed at wileyonlinelibrary.com]

Further details on the origin of the dust events over the central Sahara $\left(17-23^{\circ} \mathrm{N}, 1-7^{\circ} \mathrm{E}\right)$ during June 2011 are provided in Figures 8 and 9. Figure 9 shows time series of AOD derived from AEROIASI, an indicator of WAM northward excursions, the occurrence of haboobs associated with large MCSs (tracked with SEVIRI, as done in section 4.2) and ERA5 meridional winds at $850 \mathrm{hPa}$. The northward bursts of the WAM are depicted by the difference in equivalent potential temperature at $850 \mathrm{hPa}$ between the location of the dust hotspot $\left(17-23^{\circ} \mathrm{N}, 1-7^{\circ} \mathrm{E}\right)$ and areas $8^{\circ} \mathrm{E}$ and $8^{\circ} \mathrm{W}$ of it (i.e., the longitudinal extent of a bulge of the ITD at this latitude is less than $\sim 16^{\circ}$; e.g., Cuesta et al., 2009). A positive difference occurs for higher equivalent potential temperatures than the surrounding regions and is related to a regional northward advection of WAM air masses. The AOD time series clearly shows five periodical peaks every 3 or 4 days (on June 10, 13, 17, 20 and 23). All these dust events are clearly concomitant with both cold pools initiated by MCSs and northward bursts of the WAM (which can also be pushed northwards by cold pools). This means that in all cases dust is uplifted by both cold pools and/or the ITD acting as a density current. In addition to the northward transport of moist monsoonal air, one key factor favouring the convective activity that initiates the cold pools is probably the existence of mountains around the hotspot in central Sahara. Indeed, this is shown by the fact that haboobs in most of these cases form beneath MCSs located either over the Aïr Mountains (for the events of June 10,13, 17 and 20) or the Adrar des Ifoghas Mountains (on June 19), as shown by SEVIRI observations (see the examples of June 17 and 19 in section 4.2). At this time of year, orographic forcing appears to play an important role for convective initiation within this latitude band, as other favourable conditions (such as soil moisture) are expected to remain marginal.

Northward bursts of the WAM over the hotspot may also be favoured by synoptic conditions. This is the case for the cyclonic circulations associated with both extratropical disturbances located northwest of the Sahara at the beginning of the month (June 5 and 10; Figure 8a) and the SHL after June 16. Shortly before June 16, the SHL moves from east of $0^{\circ} \mathrm{E}$ to northern Mauritania, reinforcing the northward burst of the WAM over the hotspot particularly on June 16-17 (shown by a potential temperature anomaly at $850 \mathrm{hPa}$ over $20-25^{\circ} \mathrm{N}$ in Figure $8 \mathrm{~b}$ ). These large-scale transitions are typical for this time of year (Knippertz et al., 2017). Moreover, northward bulges of the ITD are observed over the dust hotspot $\left(17-23^{\circ} \mathrm{N}\right)$ on the last four dust events (after June 13) and each of them propagates westwards from $7^{\circ} \mathrm{E}$ to $15^{\circ} \mathrm{W}$ over the following 2 or 3 days (see the Hovmöller graph of equivalent potential temperature at $850 \mathrm{hPa}$; Figure $8 \mathrm{c}$ ). This occurs in clear concomitance with the propagation of the southerlies associated with the wave-like perturbations initiated over the hotspot (from the surface to $850 \mathrm{hPa}$; Figure $7 \mathrm{~d}, \mathrm{~g})$. This means that the intense convective activity triggered near the dust hotspot not only affects this region but also likely generates easterly propagating waves 
(a)
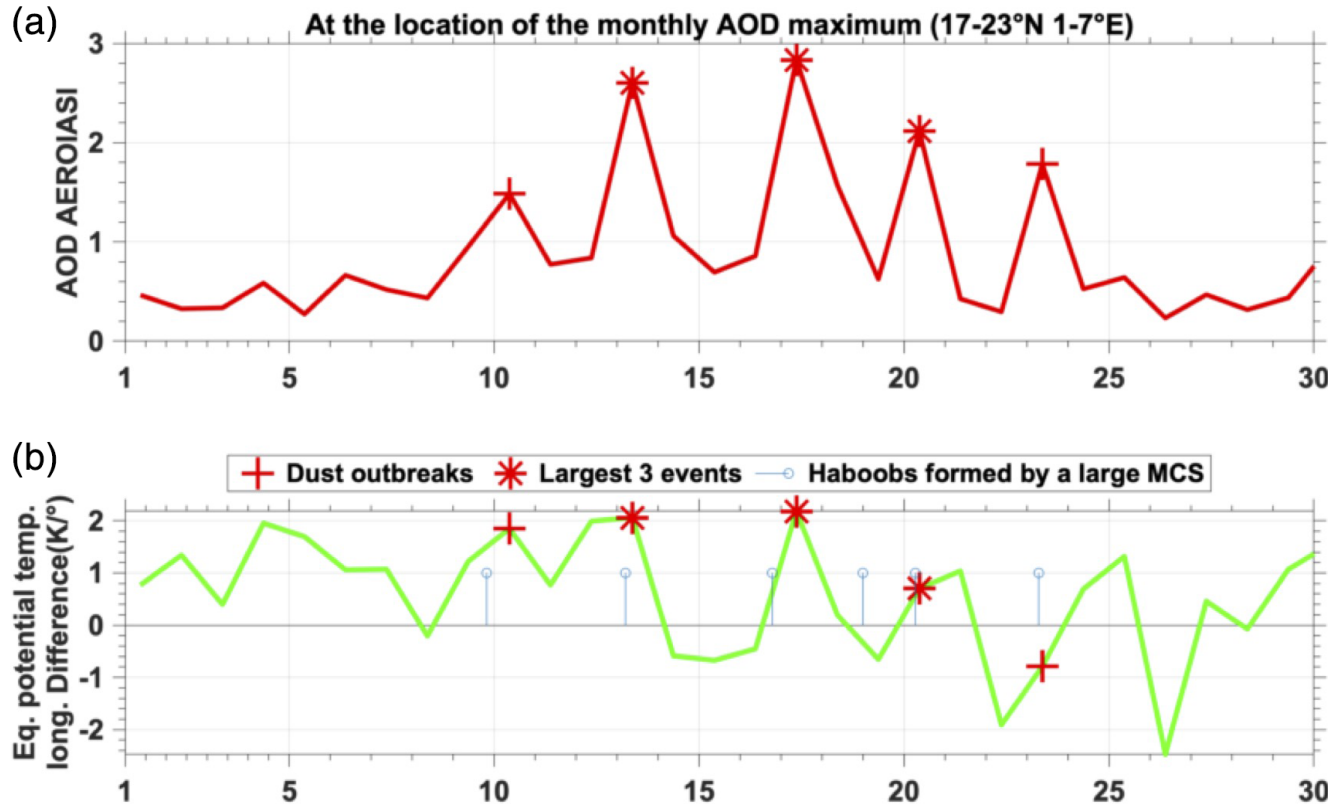

(c)

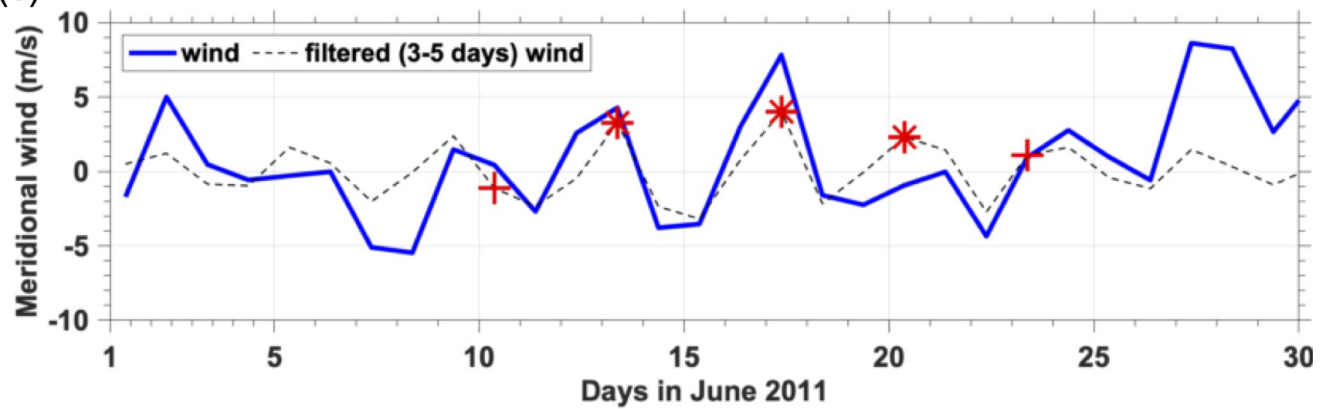

F I G U R E 9 Daily evolution at the location of the monthly AOD maximum $\left(17-23^{\circ} \mathrm{N}, 1-7^{\circ} \mathrm{E}\right)$ over the Sahara in June 2011 of (a) dust optical depth at $10 \mu \mathrm{m}$ derived from AEROIASI, (b) longitudinal difference of equivalent potential temperature at $850 \mathrm{hPa}$ used as an indicator of WAM northward excursions (green line) and occurrence of the formation of haboobs by mesoscale convective systems (MCSs) larger than $5 \times 5^{\circ}$ and reaching the hotspot (blue stems; both haboobs and MCSs tracked with SEVIRI observations as done in Figures 10a and 12a) and (c) meridional winds at $850 \mathrm{hPa}$ from ERA5 unfiltered (blue line) and filtered (black dashed line) for the 3-5 day variability associated with wave-like perturbations observed over the hotspot. Red asterisks indicate the days of the three dustiest events in concomitance with WAM bursts, cold pools and southerlies associated with waves; red crosses indicate the other two significant dust peaks [Colour figure can be viewed at wileyonlinelibrary.com]

that also favour northward bursts of the WAM west of this region. This may contribute to enhanced convection and associated dust emissions (see surface dust events concomitant with the westward-propagating southerlies associated with these waves in Figure 7i). Further investigation of the link between dust, cold pools, WAM and waves in a 3D perspective is provided in the following section for the dustiest events of the month.

\section{2 | Dust outbreaks within northward bursts of the monsoon over the central Sahara}

The largest dust outbreak over the central Sahara in June 2011 is initiated by a cold pool formed by an MCS over the Aïr Mountains $\left(18^{\circ} \mathrm{N}, 7^{\circ} \mathrm{E}\right.$; see the grey outline in Figure 10a) during the night from June 16 to 17, 2011, generating strong surface winds and the uplift of large amounts of dust (manually tracked with SEVIRI AOD images, as shown in magenta in Figure 10a). In the following hours, the dust plume becomes denser and extends over a larger region, with a leading edge moving northwestwards until it reaches southern Algeria and eastern Mali during the morning of June 17 (see AEROIASI AOD at 1000 UTC in Figure 10b). The northwestern edge of the dust plume is located just south of the ITD, as the leading edge of the MCS-generated cold pool has reached the ITD and merged with it at this time (as found by Flamant et al., 2009). This major dust plume is clearly co-located with the southerlies associated with a wave-like perturbation (probably generated by the 
17 June 2011

AOD 500 nm 0500 UTC - SEVIRI NAS3

(a)

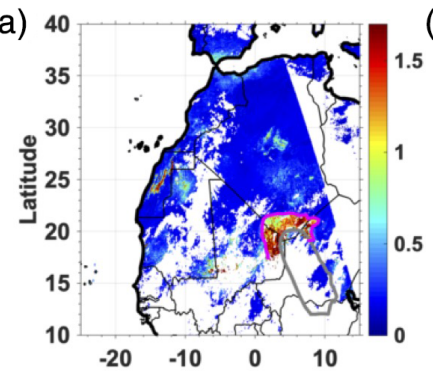

Dust extinction 0-1 km - AEROIASI

(d)

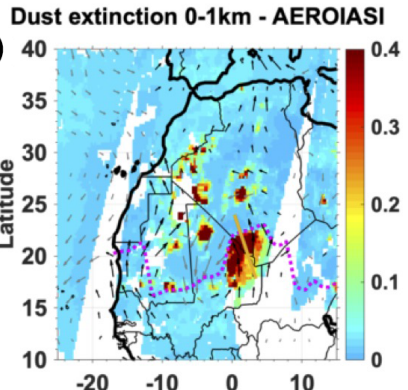

AOD $10 \mu \mathrm{m} 1000$ UTC - AEROIASI

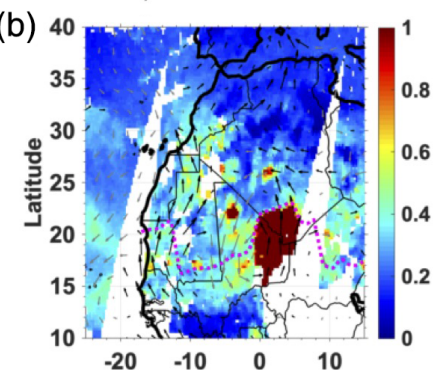

Dust extinction 2-3km - AEROIASI

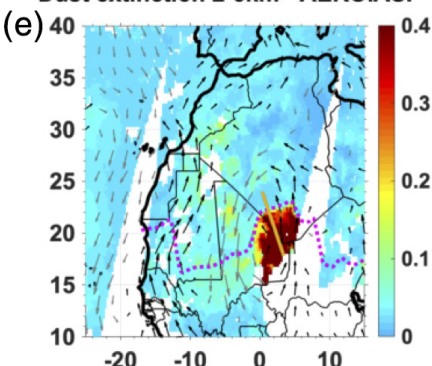

(c) 40

Dust layer height (km) - AEROIASI

Filt.(3-5 days) winds $850 \mathrm{hPa}\left(\mathrm{m} \mathrm{s}^{-1}\right)$ ERA5 Eq. Pot. Temperature (K) $850 \mathrm{hPa}$ - ERA5

Dust extinction 4-5km - AEROIASI

(f) 40

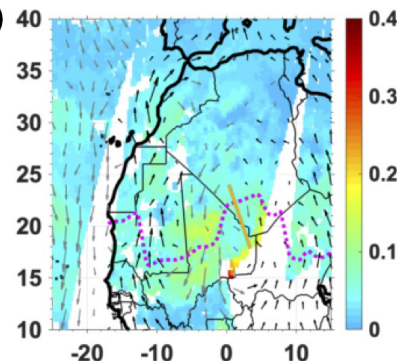

(g)

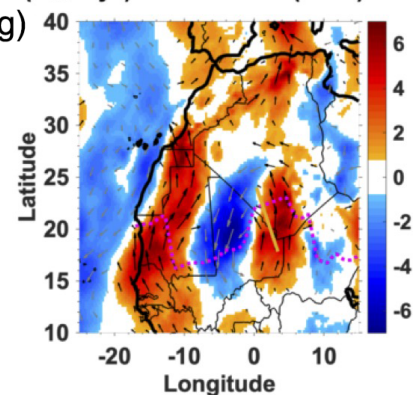

(h) 40

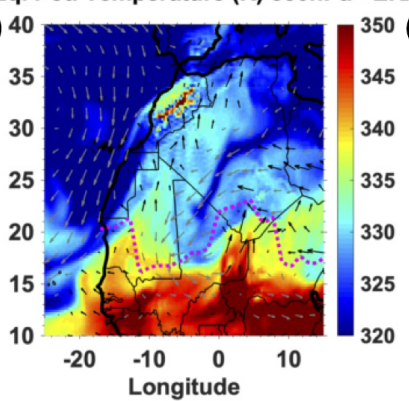

Wind $10 \mathrm{~m}\left(\mathrm{~m} \mathrm{~s}^{-1}\right)$ - ERA5

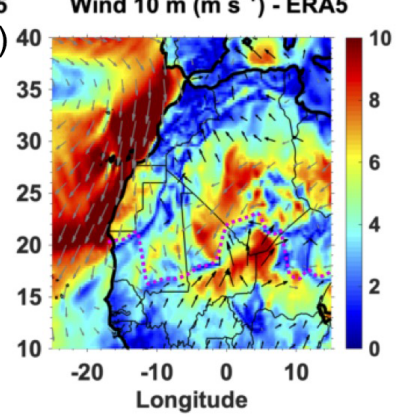

F I G U R E 10 Characterisation of dust distribution and dynamical variables on June 17, 2011 over the Sahara. (a) AOD at 0500 UTC derived from SEVIRI NAS3, (b) AOD at $10 \mu \mathrm{m}$ from AEROIASI at 1000 UTC, (c) mean dust layer height (km) above ground level and dust extinction $\left(\mathrm{km}^{-1}\right)$ at $10 \mu \mathrm{m}$ for the altitudes (d) 0-1 km, (e) 2-3 km and (f) 4-5 km. ERA5 reanalysis at $0900 \mathrm{UTC}$ of (g) filtered (3-5 days) winds at $850 \mathrm{hPa}\left(\mathrm{m} \cdot \mathrm{s}^{-1}\right)$ shown with arrows (grey and black, respectively, with southward and northward components) and meridional windspeed (colours), (h) equivalent potential temperature at $850 \mathrm{hPa}$ and (i) winds at $10 \mathrm{~m}$ above ground level. The grey and magenta solid lines in panel (a) show the location of the MCS forming the haboob at 2100 UTC the previous day and the haboob at 0500 UTC, respectively. The magenta dotted line depicts the location of the ITD (surface wind changes north of the $15^{\circ} \mathrm{C}$ dew point at $2 \mathrm{~m}$, panels [b-i]). Arrows indicate winds in panel (h) and filtered (3-5 days) winds in panels (b-g,i). The yellow line in panels (d-g) show the location of the vertical transect considered for the composite in Figure 11 [Colour figure can be viewed at wileyonlinelibrary.com]

convective activity that also forms the associated cold pool; Figure 10g).

According to AEROIASI observations, the dust plume exhibits a leading edge heading northwestwards, which extends from the surface up to $2-3 \mathrm{~km}$ of altitude (around $21^{\circ} \mathrm{N}, 2^{\circ} \mathrm{E}$; Figure $10 \mathrm{~d}-\mathrm{e}$ ) until it is $200-300 \mathrm{~km}$ behind it. Towards the rear southeastern part of the plume, dust is only observed at $2-3 \mathrm{~km}$ of altitude and it does not reach the ground (seen over a $\sim 200-\mathrm{km}$ wide band from $17^{\circ} \mathrm{N}, 2^{\circ} \mathrm{E}$ to $21^{\circ} \mathrm{N}, 4^{\circ} \mathrm{E}$ in Figure $10 \mathrm{~d}$ ). A slanted shape is depicted by the mean altitudes of the dust plume increasing by $1-1.5 \mathrm{~km}$ from $21^{\circ} \mathrm{N}, 2^{\circ} \mathrm{E}$ up to $20^{\circ} \mathrm{N}, 3^{\circ} \mathrm{E}$
(Figure 10c). At the surface, the variation of the dust load clearly agrees with ground-based measurements of a nephelometer located at Bordj Badji Mokhtar $\left(21.3^{\circ} \mathrm{N}, 0.9^{\circ} \mathrm{E}\right)$ for this particular event (see Allen et al., 2013, fig. 5). In situ measurements at the surface show a dust peak lasting for 5-6 hrs, which is consistent with the passage of a $200-300 \mathrm{~km}$ wide dust front evidenced by AEROIASI propagating at $\sim 12 \mathrm{~m} \cdot \mathrm{s}^{-1}$ (estimated from SEVIRI by Allen et al., 2013).

A very similar 3D slanted structure of the dust plume over the hotspot $\left(17-23^{\circ} \mathrm{N}, 1-7^{\circ} \mathrm{E}\right)$ is also found for the two other major dust events occurring on June 13 and 
F I G U R E 11 Composite of the 3D distribution of dust and main dynamical variables describing the WAM and African easterly waves (AEWs) for the three main peaks of dust load over the central Sahara, on the day of the AOD maximum. Transects within the area of AEW southerlies co-located with the dust plume of (a) dust vertical profiles and (b) dust extinction below $700 \mathrm{~m}$ above sea level, both derived from AEROIASI, and (c) equivalent potential temperature $(\mathrm{K})$, horizontal winds and vertical velocity from ERA5 projected on the transect. (d) 3D structures of the dust derived from AEROIASI and of the monsoonal air masses depicted by the $337 \mathrm{~K}$ isentrope of the ERA5 reanalysis and the location of southerlies (red arrows), northerlies (blue arrows) and troughs (shading at the surface level) associated with wave-like perturbations depicted by filtered (3-5 days) ERA5 winds and geopotential height anomalies, both at $850 \mathrm{hPa}$. Isentropes of equivalent potential temperature and projected winds are overlaid on the dust transect of panel (a). Averaging of the three cases (June 13, 17 and 20,2011 ) is done by prior normalisation of latitude and longitude, by considering $0^{\circ}$ relative latitudes/longitudes as the location of the northward dust front within the southerlies of the wave-like perturbations [Colour figure can be viewed at wileyonlinelibrary.com] (a)

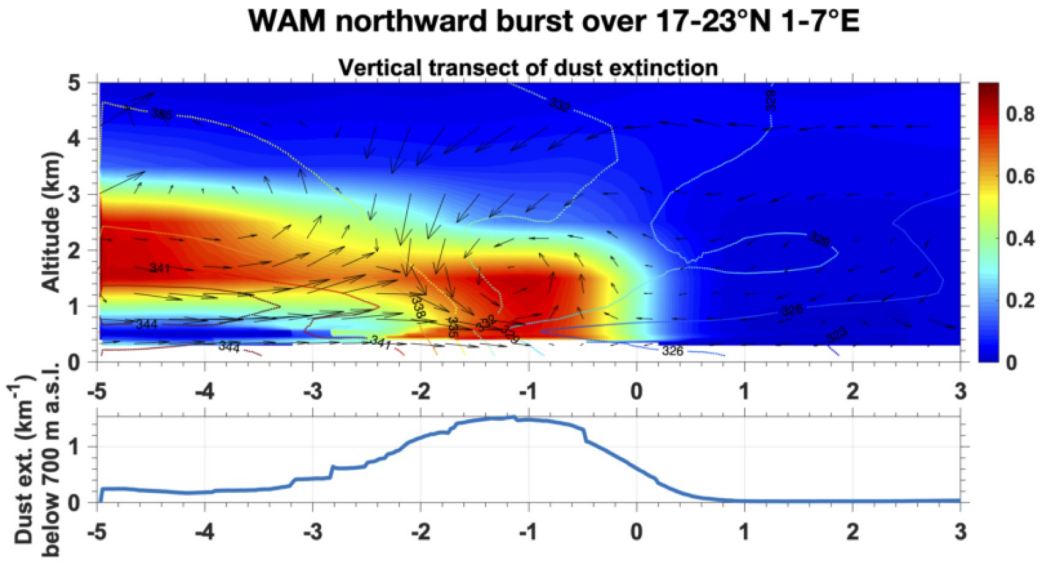

(c)

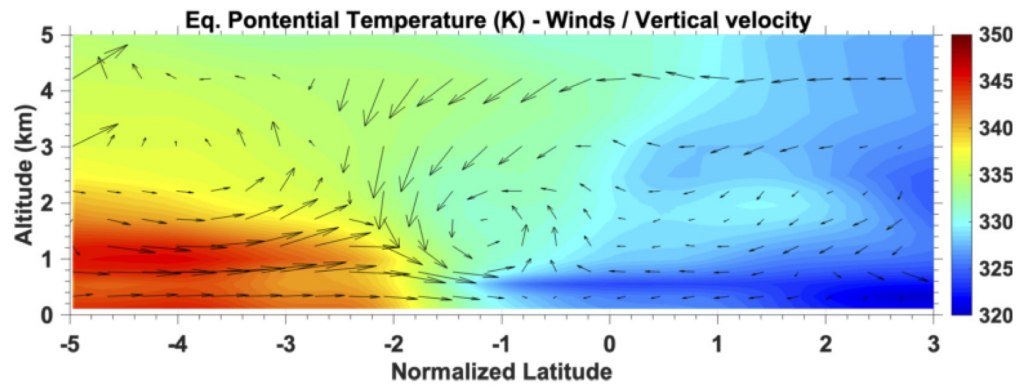

(d)

3D distribution of dust

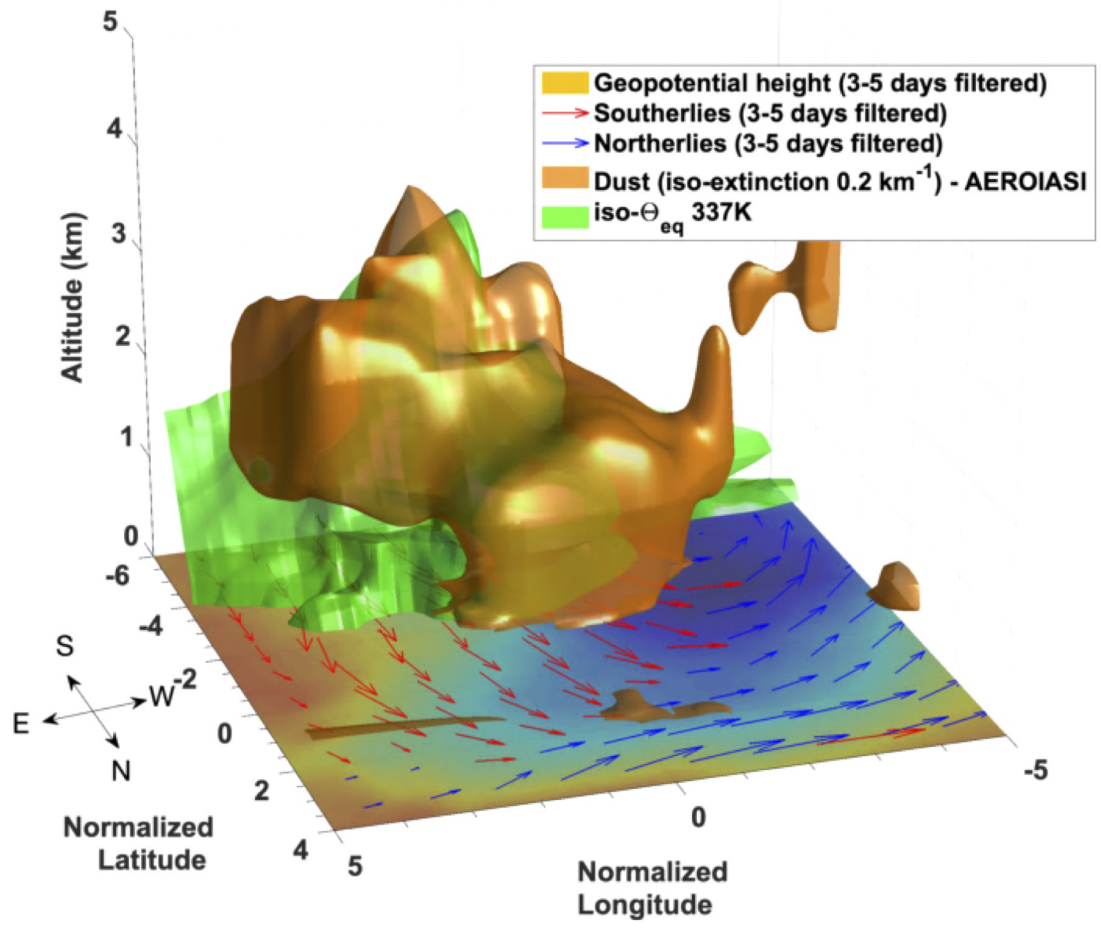

20,2011 , in concomitance with cold pools and northward excursions of the WAM. A detailed description of the 3D structure of dust and the associated dynamical features is presented in Figure 11 as a 3D composite view of the three dustiest events (June 13, 17 and 20, indicated by asterisks in Figure 9). This composite can only be done with daily observations of the full 3D distribution of dust over the region, as provided by AEROIASI. Before averaging, we define a " 0 " normalised latitude and longitude" as the location on the leading edge of the dust front embedded within the strongest southerlies associated with the WAM burst. Then, we composite the 3D dust extinction, equivalent potential temperature and wind fields of the three events and represent them as transects (Figure 11a,c) and graphs of iso-extinction and equivalent isentrope for the 3D distributions of dust and monsoonal air, respectively 
19 June 2011

AOD $500 \mathrm{~nm} 0500$ UTC - SEVIRI NAS3

(a) 40

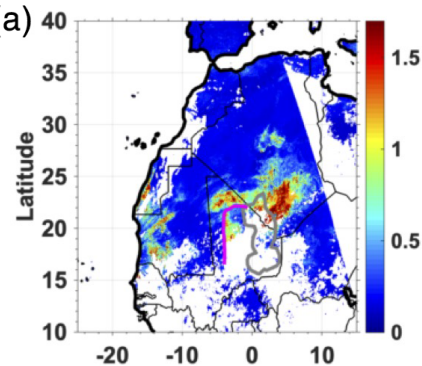

(b)

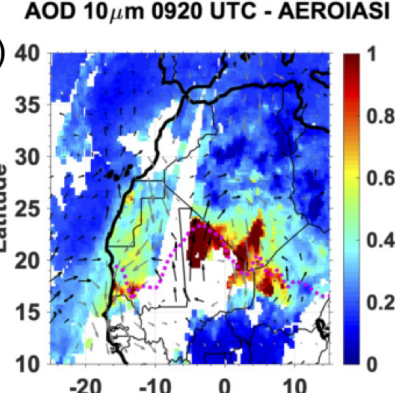

Dust extinction 0-1km - AEROIASI

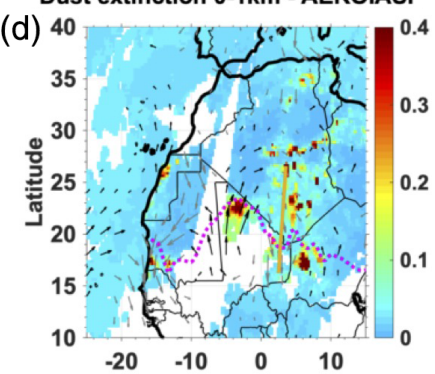

Dust extinction 2-3km - AEROIASI

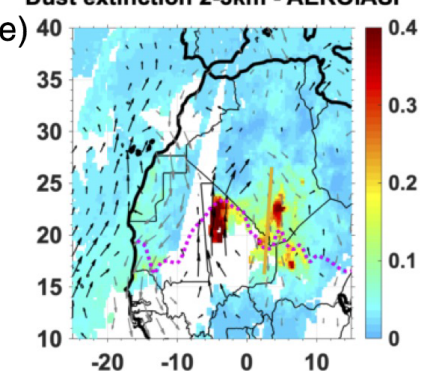

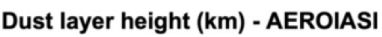

(c) 40

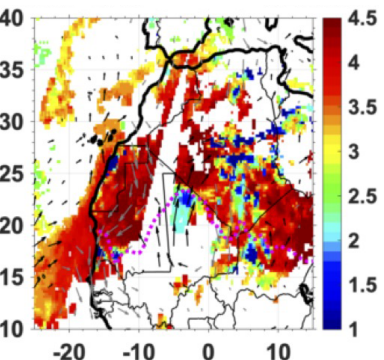

Dust extinction 4-5km - AEROIASI

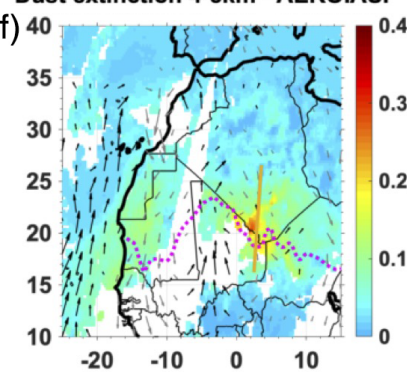

Filt.(3-5 days) winds $850 \mathrm{hPa}\left(\mathrm{m} \mathrm{s}^{-1}\right)$ ERA5 Eq. Pot. Temperature (K) $850 \mathrm{hPa}$ - ERA5
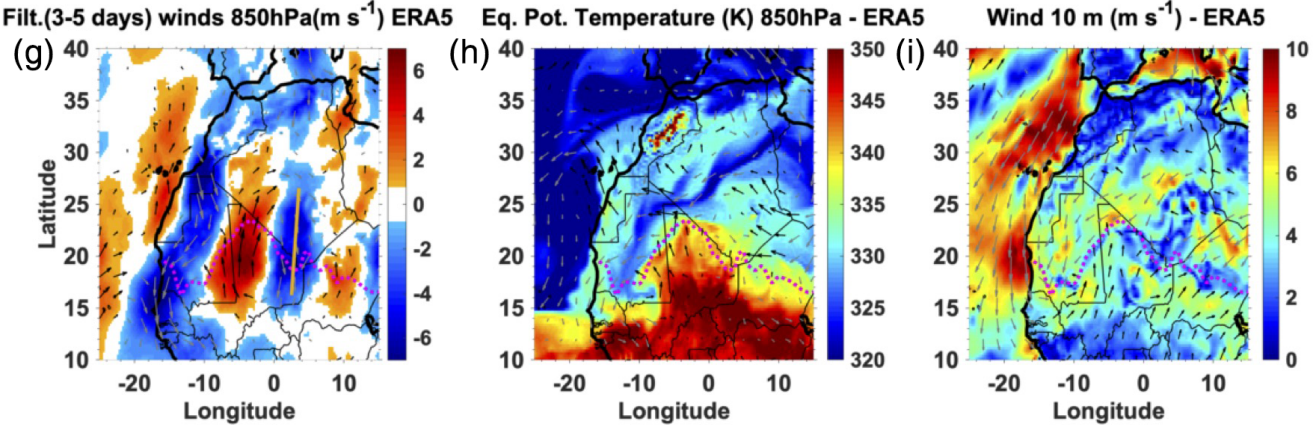

F I G U R E 12 As Figure 10, but for June 19, 2011. AEROIASI retrievals are shown at 0920 UTC [Colour figure can be viewed at wileyonlinelibrary.com]

(Figure 11d). This figure shows that the distribution of dust on the day of maximum AOD over the hotspot is consistently characterised by a dense dust front, extending from the surface up to $\sim 2 \mathrm{~km}$ of altitude at the leading edge until it is about $2-3^{\circ}$ behind it (Figure 11a,b). Behind this location (normalised latitude between -5 and $-3^{\circ}$ in Figure 11a), the dust plume elevates up to $3.5 \mathrm{~km}$ of altitude and the near-surface dust load is as low as in clean air, probably related to the monsoon flow. At the surface, dust loads are highest at the leading edge of the cold pool over a distance of $3^{\circ}$ (approximately $300 \mathrm{~km}$; Figure 11b) and decrease towards the rear of the plume, as found for the case of June 17. The 3D image (Figure 11d) shows a rather rounded transversal shape of the dust front, where the leading edge is likely entrained westwards by the cyclonic circulation around the trough of the concomitant wave (see the dust plume front reaching the surface closer to the vortex).
The 3D slanted structure of the dust plume is consistent with the occurrence of dust uplift at the leading edge of the cold pool and the subsequent transport of dust that elevates progressively following the slanted isentropes at the interface of the denser monsoon flow and the Saharan air layer (SAL) above (see Figure 11a,c). A wind curl is seen behind/south of the leading edge of the dust front (Figure 11a), which could be related to a perturbation of the large-scale shallow circulation by the monsoon northward burst. A similar 3D slanted structure of the dust plume is also found up to 2 days after the AOD maxima within the area of southerlies behind the associated wave trough (after westward propagation of $3-4^{\circ}$ in longitude per day; see Figure 12b,g). This is observed on June 19 when the dust plume initially uplifted over the central Saharan hotspot reaches northwestern Mali and eastern Mauritania, still co-located with southerlies associated with a wave-like perturbation (see northern Mali in 
Figure 12b,g). The dust of this plume has not only been emitted on June 17 but also on the evening of June 18 by an additional haboob formed by an MCS over the Adrar des Ifoghas Mountains (grey outline in Figure 12a). The northern part of the haboob is located just south of the ITD (reaching $23^{\circ} \mathrm{N}$ at these longitudes), extending from the ground up to $2-3 \mathrm{~km}$ over northern Mali (at $23^{\circ} \mathrm{N}$, $3^{\circ} \mathrm{W}$ in Figure $12 \mathrm{~d}$ ) and dust is only seen $2-3 \mathrm{~km}$ south of this region. The main differences with respect to the day of maximum AOD over the hotspot are a reduction of the dust amount by a factor of 2-3 and a less homogenous frontal structure of the dust plume.

Dust plumes with a slanted structure at the rear of the leading edge have previously been evidenced using airborne lidar observations (Bou Karam et al., 2008; Flamant et al., 2007, 2009), but only in 2D (along the aircraft track). AEROIASI shows here the first 3D observation of such dust frontal phenomena associated with the WAM, cold pool and wave activity.

\section{ISENTROPIC UPGLIDING OF DUST DURING THE RETREAT OF THE MONSOON}

During the period June 13-23, the central Saharan hotspot $\left(17-23^{\circ} \mathrm{N}, 1-7^{\circ} \mathrm{E}\right)$ is reached by northerlies ahead of wave troughs approximately 2 days after large dust outbreaks are triggered over this area. We analyse the 3D distribution of dust during this situation at the daily scale (on June 19 in Figure 12) and from a composite of three similar cases occurring 2 days after the dust events over the hotspot (June 15, 19 and 22 in Figure 13). Both viewpoints (June 19 and the three-case composite) show a contrasting situation when northerlies blow over the central Saharan hotspot with respect to that associated with southerlies, in terms of the 3D distribution of dust. In the absence of a northward surge of the WAM, dust plumes reaching the surface are mainly observed north of the ITD, which is located at the southern edge of the hotspot (around $19^{\circ} \mathrm{N}$; Figure 12d). South of the ITD, elevated dust layers are seen at 2-5 $\mathrm{km}$ of altitude above monsoonal air (depicted by the $337 \mathrm{~K}$ isentrope iso-surface in Figure 13d). Most of the dust layers located south of the ITD do not reach the ground. Contrary to the situation over the area of southerlies, these dust plumes are transported by isentropic upgliding with the residual SAL, which is advected southwards above the monsoonal air.

\section{6 | SUMMARY}

This article presents a new characterisation of the 3D distribution of dust and the link with the main WAM-related dynamic drivers over the central Sahara during June 2011, using hyperspectral satellite observations from IASI. This is the first analysis of daily observations of the full 3D distribution of dust over the Sahara, which are derived using the AEROIASI approach. Comparisons with independent datasets presented in this paper confirm good performance of AEROIASI over the Sahara. For vertically integrated AOD of Saharan dust, AEROIASI shows a low mean bias (0.02), a good correlation (0.90) and a moderate mean squared difference (0.18) as compared with AERONET sun photometer measurements from 11 stations across the Sahara during June 2011. In a comparison of the horizontal distribution of AOD, AEROIASI shows similar performance in relative terms on the location and structure of dust plumes with respect to other satellite observations (SEVIRI, MODIS and OMI) and a better quantitative match with two SEVIRI products (ICL and NAS3). Transects of vertical profiles of dust extinction across the Sahara are in very good agreement with CALIOP space-borne lidar data, in terms of the vertical structure of dust layers along the track. This threefold validation using AODs as well as the horizontal and vertical distributions of dust gives confidence in AEROIASI observations for analysing the dynamical drivers of the 3D distribution of Saharan dust.

According to a monthly average of AOD and 3D distribution of dust extinction from AEROIASI, we clearly identify the dustiest spot of the Sahara during June 2011 at the triple frontier of Algeria, Mali and Niger $\left(17-23^{\circ} \mathrm{N}\right.$, $\left.1-7^{\circ} \mathrm{E}\right)$ over the central Sahara. In this region, dust is distributed vertically from the surface up to $5 \mathrm{~km}$ of altitude, with the highest monthly dust loads from 3 to $5 \mathrm{~km}$ of altitude. A daily time series of AOD over this area reveals a periodical evolution of dust abundance, with five major peaks during the month occurring every 3-4 days. Our study shows that all these dust load peaks are indeed concomitant in time and space, with northward excursions of the WAM and cold pools generated by convective activity. Convective initiation is enhanced by the presence of the Aïr and Adrar des Ifoghas Mountains to the east and west of the hotspot.

Two clearly distinct regimes in terms of atmospheric conditions over northern Africa are observed before and after June 13, 2011 (see schematics in Figure 14). At the beginning of the month, extratropical disturbances located northwest of Morocco significantly affect atmospheric circulation as far as the central Sahara. The cyclonic circulation associated with these troughs favours the occurrence of northward bursts of the WAM and the associated southerly advection of moist air over the hotspot. This occurs during two dust outbreaks over this region: a moderate event on June 5 and a major one on June 10. These dust plumes are not remotely transported, as zonal winds 
Northerlies over $17-23^{\circ} \mathrm{N} 1-7^{\circ} \mathrm{E}$

(a)

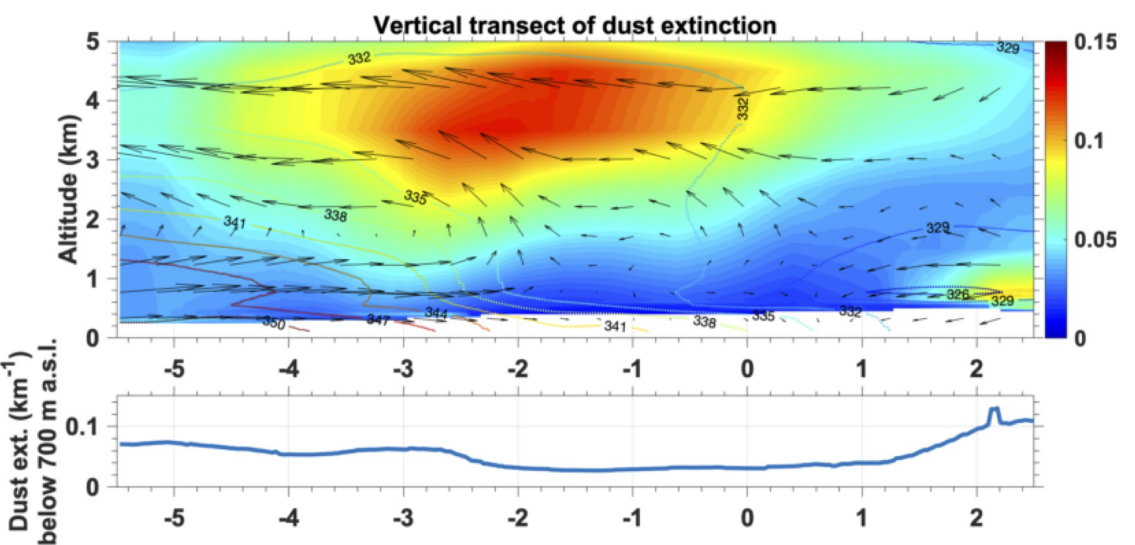

(c)

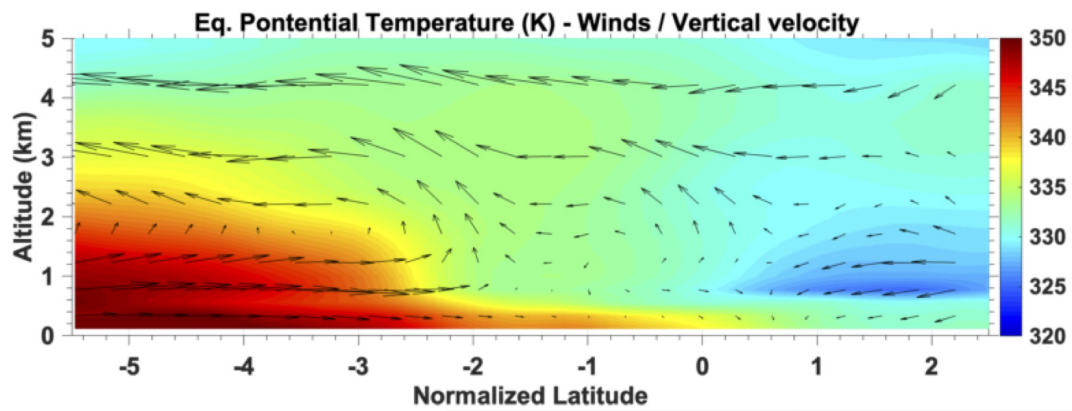

(d)

\section{D distribution of dust}

Geopotential height (3-5 days filtered)

$\rightarrow$ Southerlies (3-5 days filtered)

$>$ Northerlies (3-5 days filtered)

Dust (iso-extinction $0.07 \mathrm{~km}^{-1}$ ) - AEROIASI iso- $\Theta_{\text {eq }} 337 \mathrm{~K}$

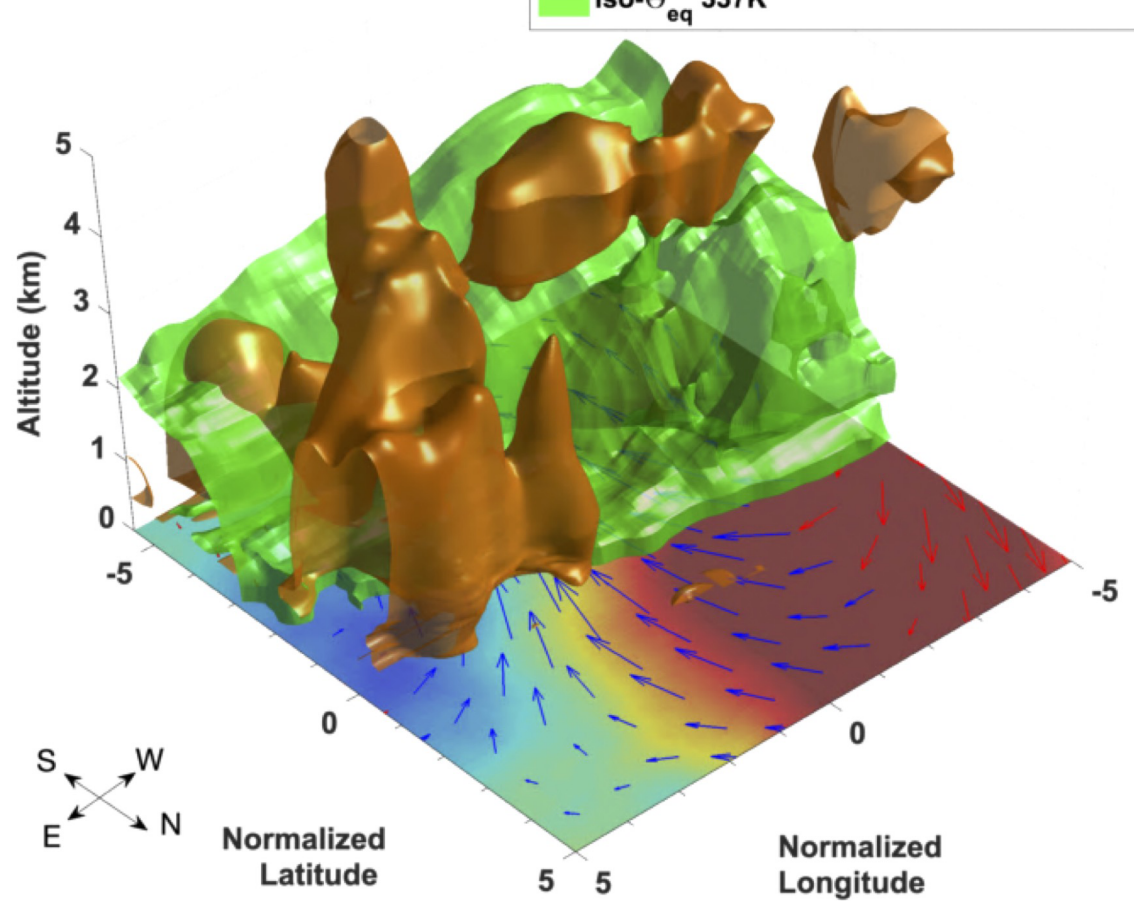

F I G U RE 13 As Figure 11, but for composite dust and dynamical fields within the area northerlies associated with wave-like perturbations over the dust hotspot $\left(17-23^{\circ} \mathrm{N} 1-7^{\circ} \mathrm{E}\right)$, occurring 2 days after the AOD maxima (i.e., June 15, 19 and 22, 2011) [Colour figure can be viewed at wileyonlinelibrary.com] are perturbed by the extratropical troughs and the AEJ is still located south of the hotspot.

After June 13, no more major extratropical disturbances are seen to directly affect the ITD region and the AEJ moves north until it reaches the hotspot. During this period and in the latitude band $17-23^{\circ} \mathrm{N}$, elevated dust layers between 2 and $5 \mathrm{~km}$ are visibly transported westwards by the AEJ (from the longitude band $0-10^{\circ} \mathrm{E}$ to $20-10^{\circ} \mathrm{W}$ ). Over the hotspot, intense convection activity forms a succession of four haboobs every 3 or 4 days (on June 13, 


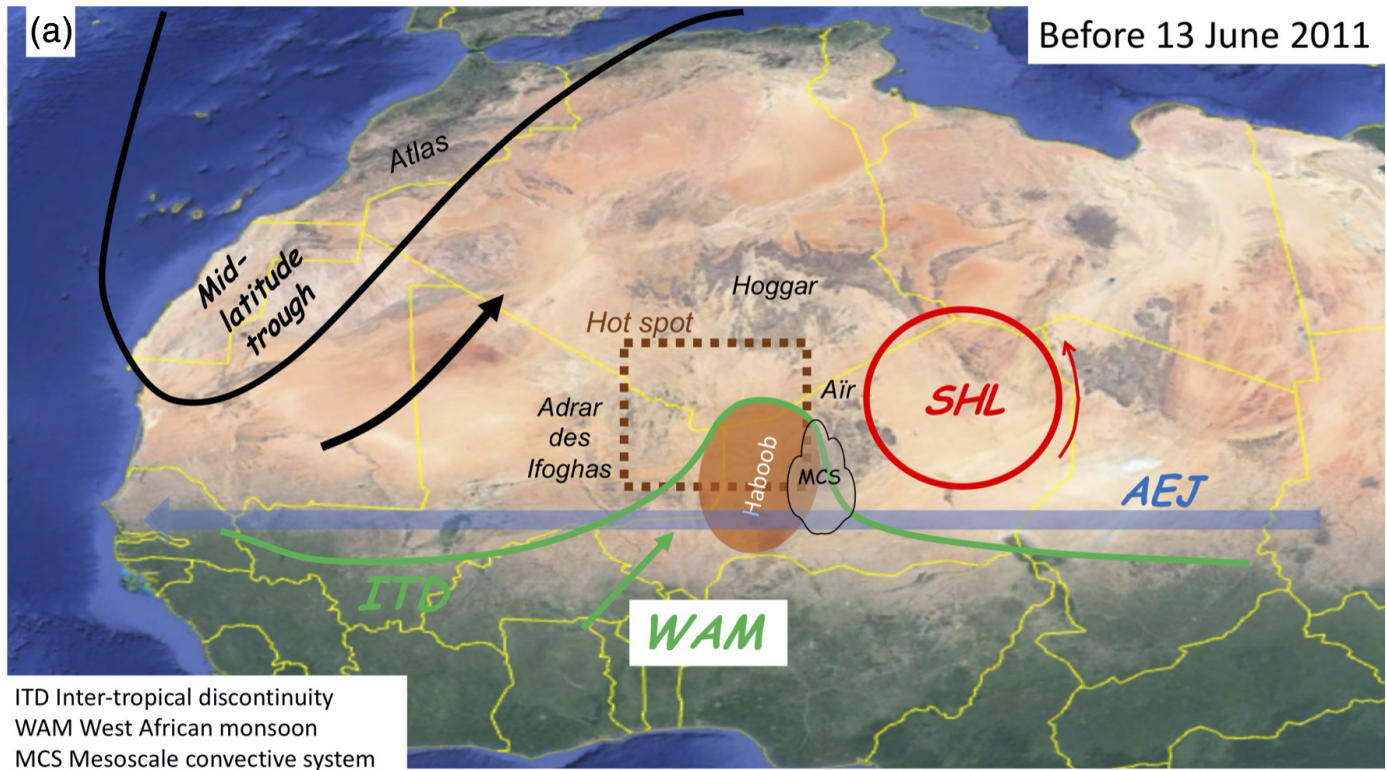

MCS Mesoscale convective system

SHL Saharan heat low

AEJ African easterly jet

T wave trough

$\mathrm{R}$ wave ridge

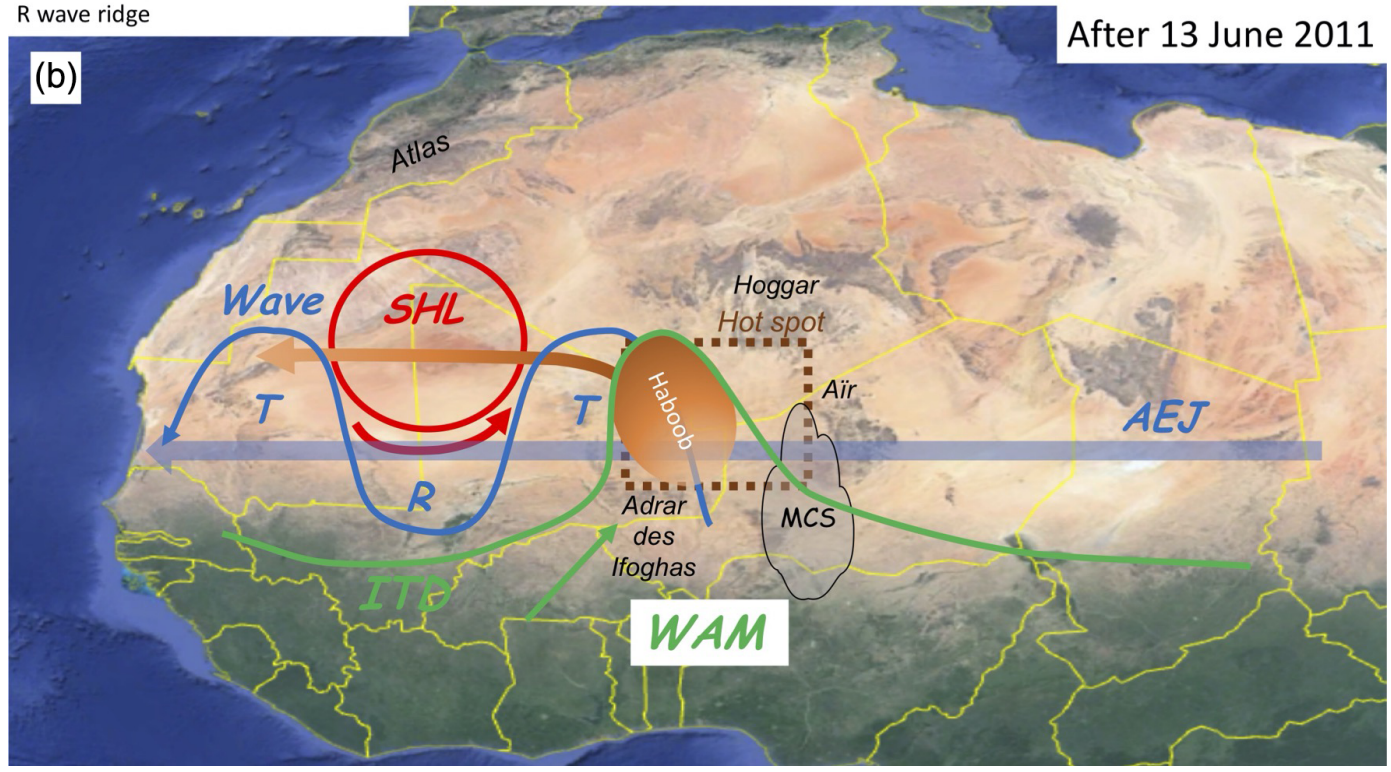

F I G U R E 14 Schematic of the atmospheric dynamical conditions over West Africa leading to major dust emission over the central Sahara hotspot $\left(17-23^{\circ} \mathrm{N} 1-7^{\circ} \mathrm{E}\right)$ during June 2011, (a) before and (b) after June 13, 2011. Brown shading indicates the location of the major dust plume emitted over the hotspot and its vertical distribution (darker and lighter brown shades for dust extending from the surface to $2 \mathrm{~km}$ of altitude and above $2 \mathrm{~km}$, respectively). The brown arrow shows westward transport of dust by the African easterly jet (AEJ) [Colour figure can be viewed at wileyonlinelibrary.com]

17, 20 and 23) and also generates wave-like perturbations that propagate westwards along the AEJ. These waves have periods of 3-5 days, as do those of typical AEWs, but they differ with respect to other properties (e.g., altitude of maximum intensity, propagation speed and wavelength). Both phenomena - haboobs and waves - contribute to the occurrence of concomitant northward bulges of the ITD over the hotspot, which then propagate westwards in concomitance with the southerlies behind the trough of the wave-like perturbations in the following 2 or 3 days. Shortly before
June 16, the SHL moves westwards until it reaches northern Mauritania and intensifies. After June 16, the cyclonic circulation associated with the SHL is added as a third factor favouring the northward surge of the WAM over the hotspot.

Additional insights on how dynamical drivers affect the 3D distribution of dust are obtained from the analysis of (a) the dustiest event of the month between June 17 and 19, 2011, and (b) a composite of the three dustiest events coincident with northward excursions of the WAM 
(on June 13, 17 and 20). On the day of maximum AOD over the hotspot at the triple frontier of Algeria, Niger and Mali an elongated dust front is transported northwards by the southerlies associated with the convective activity over the area. The leading edge of the dust plume extends from the surface up to $2 \mathrm{~km}$ of altitude and its tail progressively elevates up to $3.5 \mathrm{~km}$ until it is $500 \mathrm{~km}$ behind the leading front. Around $200 \mathrm{~km}$ behind the front dust, surface concentrations drop and a slanted layer of dust elevates over clean air beneath (probably brought in by the monsoon flow behind the frontal structure). Haboobs formed the night before also play a role as an efficient mechanism for dust uplift and contribute to the formation of the dust front. Once uplifted, these dust plumes are advected northwestwards by the cyclonic vortex circulation at the trough of a wave-like perturbation generated by convection over the hotspot, still forming a leading edge extending from the surface to about $2 \mathrm{~km}$ of altitude, but less abundant in terms of dust load and with a less sharp frontal structure. A contrasting situation is found in the absence of northward bursts of the WAM, where most dust is observed at elevated atmospheric layers around $3-5 \mathrm{~km}$ and thus where the SAL is transported slantwise southwards following the ascending isentropes above the WAM layer.

These results show new observational evidence of the importance of the WAM, cold pools, extratropical disturbances and the SHL as drivers of the 3D distribution of dust over the central Sahara during summer. Future studies of the 3D distribution of dust based on AEROIASI data will enable a quantitative estimation of the role of these mechanisms in the emission and transport of Saharan dust at the climatological scale. These analyses will provide valuable information on dust vertical mixing processes, which are difficult to model and play a crucial role in the diurnal cycle. New insights into dust emission occurrence and location may be provided by AEROIASI in combination with back trajectories, given its capability to depict dust variability near the surface with fewer ambiguities than standard vertically integrated satellite measurements. AEROIASI will also be used for validating model simulations of the horizontal and vertical distribution of dust, with the latter currently very rarely validated. In addition, AEROIASI observations provide a new and unique 3D constraint for models via data assimilation, as current state-of-the-art systems only assimilate the horizontal distribution of AOD, typically provided by MODIS (e.g., Bozzo et al., 2020).

\section{ACKNOWLEDGEMENTS}

The authors are grateful for the financial support given by the Centre National des Etudes Spatiales (CNES, the French Space Agency; IASI project/Terre, Océan, Surfaces continentals, Atmosphère), the Programme National de
Télédétection Spatiale (PNTS, http://programmes.insu. cnrs.fr/pnts; grant no. PNTS-2013-05, project "SYNAEROZON") and the Agence Nationale de la Recherche (ANR grant 2010 BLAN 606 01) for enabling this research work and its publication. This study is also supported by the Université Paris Est Créteil (UPEC) and the Centre National des Recherches Scientifiques - Institut National des Sciences de l'Univers (CNRS-INSU). We thank the Institut für Meteorologie und Klimaforschung of the Karlsruhe Institute of Technology (Germany) for providing the KOPRA radiative transfer code for processing the IASI data. IASI is a joint mission of EUMETSAT and CNES. We acknowledge Jamie Banks from Imperial College London (United Kingdom) and Louis Gonzalez from the Laboratoire d'Optique Atmosphérique (France) for providing their SEVIRI aerosol products (called respectively here SEVIRI ICL and SEVIRI NAS3; http://nascube. univ-lille1.fr), the AERONET network for sun photometer observations over the Sahara (http://aeronet.gsfc.nasa. gov), the data centres AERIS (https://www.aeris-data.fr) for the level 1 data of IASI (originally supplied by EUMETSAT; http://www.eumetsat.int) and the GIOVANNI portal (https://giovanni.gsfc.nasa.gov) for the MODIS and OMI level 3 datasets. Meteorological reanalyses produced by ECMWF and CALIOP measurements (originally from NASA; http://ladsweb.nascom.nasa.gov) are supplied by CLIMSERV (http://climserv.ipsl.polytechnique.fr). Moreover, we would like to thank Richard Washington from Keble College (Oxford, UK), John Marsham from the University of Leeds (Leeds, UK) and Claire Ryder from the University of Reading (Reading, UK) for kindly providing some ancillary data (useful for discussions, although not directly used in the paper). We acknowledge F. Aires from LERMA/Observatoire de Paris for providing the surface emissivity database used for processing IASI data.

\section{ORCID}

Juan Cuesta (1) https://orcid.org/0000-0001-9330-6401

Cyrille Flamant (iD https://orcid.org/0000-0002-8309-6495

Marco Gaetani (D) https://orcid.org/0000-0003-2923-6773

Peter Knippertz (1) https://orcid.org/0000-0001-9856-619X

Andreas H. Fink (1) https://orcid.org/0000-0002-5840-2120

\section{REFERENCES}

Allen, C.J., Washington, R. and Engelstaedter, S. Dust emission and transport mechanisms in the central Sahara: Fennec ground-based observations from Bordj Badji Mokhtar, June 2011. Journal of Geophyical Research 118(12), 6212-6232.

Bangert, M., Nenes, A., Vogel, B., Vogel, H., Barahona, D., Karydis, V.A., Kumar, P., Kottmeier, C. and Blahak, U. (2012) Saharan dust event impacts on cloud formation and radiation over Western Europe. Atmospheric Chemistry and Physics, 12, 4045-4063. https://doi.org/10.5194/acp-12-4045-2012. 
Banks, J.R. and Brindley, H.E. (2013) Evaluation of MSG-SEVIRI mineral dust retrieval products over North Africa and the Middle East. Remote Sensing of Environment, 128, 58-73.

Banks, J.R., Brindley, H.E., Flamant, C., Garay, M.J., Hsu, N.C., Kalashnikova, O.V., Klüser, L. and Sayer, A.M. (2013) Intercomparison of satellite dust retrieval products over the west African Sahara during the Fennec campaign in June 2011. Remote Sensing of Environment, 136, 99-116.

Berthier, S., Chazette, P., Couvert, P., Pelon, J., Dulac, F., Thieuleux, F., Moulin, C. and Pain, T. (2006) Desert dust aerosol columnar properties over ocean and continental Africa from Lidar in-space technology experiment (LITE) and Meteosat synergy. Journal of Geophysical Research: Atmospheres, 111, D21202. https://doi.org/ 10.1029/2005JD006999.

Bock, O., Bouin, M.N., Doerflinger, E., Collard, P., Masson, F., Meynadier, R., Nahmani, S., Koite, M., Gaptia Lawan Balawan, K., Dide, F., Ouedraogo, D., Pokperlaar, S., Ngamini, J.-B., Lafore, J.-P., Janicot, S., Guichard, F. and Nuret, M. (2008) West African monsoon observed with ground-based GPS receivers during African monsoon multidisciplinary analysis (AMMA). Journal of Geophysical Research: Atmospheres, 113, D21105. https://doi.org/ 10.1029/2008JD010327.

Bou Karam, D., Flamant, C., Knippertz, P., Reitebuch, O., Pelon, J., Chong, M. and Dabas, A. (2008) Dust emissions over the Sahel associated with the West African monsoon inter-tropical discontinuity region: a representative case study. Quarterly Journal of the Royal Meteorological Society, 134, 621-634.

Bozzo, A., Benedetti, A., Flemming, J., Kipling, Z. and Rémy, S. (2020) An aerosol climatology for global models based on the tropospheric aerosol scheme in the Integrated Forecasting System of ECMWF. Geoscientific Model Development. 13(3), 1007-1034.

Brindley, H.E. and Russell, J.E. (2009) An assessment of Saharan dust loading and the corresponding cloud-free longwave direct radiative effect from geostationary satellite observations. Journal of Geophysical Research: Atmospheres, 114(D23), D23201.

Callewaert, S., Vandenbussche, S., Kumps, N., Kylling, A., Shang, X., Komppula, M., Goloub, P. and De Mazière, M. (2019) The mineral aerosol profiling from infrared radiances (MAPIR) algorithm: version 4.1 description and evaluation. Atmospheric Measurement Techniques, 12, 3673-3698. https://doi.org/10.5194/amt-123673-2019.

Capelle, V., Chédin, A., Pondrom, M., Crevoisier, C., Armante, R., Crepeau, L. and Scott, N.A. (2018) Infrared dust aerosol optical depth retrieved daily from IASI and comparison with AERONET over the period 2007-2016. Remote Sensing of Environment, 206, $15-32$.

Cattrall, C.,.J., Reagan, K.T. and Dubovik, O. (2005) Variability of aerosol and spectral lidar and backscatter and extinction ratios of key aerosol types derived from selected Aerosol Robotic Network locations. Journal of Geophysical Research: Atmospheres, 110(D10)), D10S11. https://doi.org/10.1029/2004JD005124.

Chaboureau, J.P., Flamant, C., Dauhut, T., Kocha, C., Lafore, J.P., Lavaysse, C., Marnas, F., Mokhatari, M., Pelon, J., Reinares, M.I., Schepanski, K. and Tulet, P. (2016) Fennec dust forecast intercomparison over the Sahara in June 2011. Atmospheric Chemistry and Physics, 16, 6977-6995. https://doi.org/10.5194/acp-166977-2016.

Couvreux, F., Guichard, F., Bock, O., Lafore, J.-P. and Redelsperger, J.L. (2009) Monsoon flux pulsations over West Africa prior to the monsoon onset. Quarterly Journal of the Royal Meteorological Society, 136(S1), 159-173.

Cuesta, J., Edouart, D., Mimouni, M., Flamant, P.H., Loth, C., Gibert, F., Marnas, F., Bouklila, A., Kharef, M., Ouchène, B., Kadi, M. and Flamant, C. (2008) Multiplatform observations of the seasonal evolution of the Saharan atmospheric boundary layer in Tamanrasset, Algeria, in the framework of the African Monsoon Multidisciplinary Analysis field campaign conducted in 2006. Journal of Geophysical Research: Atmospheres, 113, D00C07. https://doi. org/10.1029/2007JD009417.

Cuesta, J., Eremenko, M., Flamant, C., Dufour, G., Laurent, B., Bergametti, G., Hopfner, M., Orphal, J. and Zhou, D. (2015) Three-dimensional distribution of a major desert dust outbreak over East Asia in March 2008 derived from IASI satellite observations. Journal of Geophysical Research: Atmospheres, 120, 7099-7127.

Cuesta, J., Lavaysse, C., Flamant, C., Mimouni, M. and Knippertz, P. (2010) Northward bursts of the West African monsoon leading to rainfall over the Hoggar Massif, Algeria. Quarterly Journal of the Royal Meteorological Society, 136(S1), 174-189.

Cuesta, J., Marsham, J., Parker, D. and Flamant, C. (2009) Dynamical mechanisms controlling the vertical redistribution of dust and the thermodynamic structure of the West Saharan atmospheric boundary layer during summer. Atmospheric Science Letters, 10, 34-42. https://doi.org/10.1002/asl.207.

DeSouza-Machado, S.G., Strow, L.L., Imbiriba, B., McCann, K., Hoff, R.M., Hannon, S.E., Martins, J.V., Tanré, D., Deuzé, J.L., Ducos, F. and Torres, O. (2010) Infrared retrievals of dust using AIRS: comparisons of optical depths and heights derived for a North African dust storm to other collocated EOS A-Train and surface observations. Journal of Geophysical Research: Atmospheres, 115(D15), D15201.

Di Biagio, C., Boucher, H., Caquineau, S., Chevaillier, S., Cuesta, J. and Formenti, P. (2014) Variability of the infrared complex refractive index of African mineral dust: experimental estimation and implications for radiative transfer and satellite remote sensing. Atmospheric Chemistry and Physics, 14, 11093-11116.

Dunion, J.P. and Velden, C.S. (2004) The impact of the Saharan air layer on Atlantic tropical cyclone activity. Bulletin of the American Meteorological Society, 85(3), 353-365.

Evan, A.T., Flamant, C., Lavaysse, C., Kocha, C. and Saci, A. (2015) Water vapor-forced greenhouse warming over the Sahara Desert and the recent recovery from the Sahelian drought. Journal of Climate, 28(1), 108-123.

Fernald, F.G. (1984) Analysis of atmospheric lidar observations: some comments. Applied Optics, 23(5), 652-653.

Fernald, F.G., Herman, B.M. and Reagan, J.A. (1972) Determination of aerosol height distributions by lidar. Journal of Applied Meteorology, 11, 482-489.

Fink, A.H. and Reiner, A. (2003) Spatiotemporal variability of the relation between African Easterly Waves and West African squall lines in 1998 and 1999. Journal of Geophysical Research: Atmospheres, 108, 4332. https://doi.org/10.1029/2002JD002816.

Flamant, C., Chaboureau, J.-P., Parker, D.J., Taylor, C.M., Cammas, J.-P., Bock, O., Timouk, F. and Pelon, J. (2007) Airborne observations of the impact of a convective system on the planetary boundary layer thermodynamics and aerosol distribution in the inter-tropical discontinuity region of the West African Monsoon. Quarterly Journal of the Royal Meteorological Society, 133, 1175-1189. 
Flamant, C., Knippertz, P., Parker, D.J., Chaboureau, J.-P., Lavaysse, C., Agusti-Panareda, A. and Kergoat, L. (2009) The impact of a mesoscale convective system cold pool on the northward propagation of the intertropical discontinuity over West Africa. Quarterly Journal of the Royal Meteorological Society, 135, 139-159.

Francis, D., Alshamsi, N., Cuesta, J., Gokcen Isik, A. and Dundar, C. (2019) Cyclogenesis and density currents in the Middle East and the associated dust activity in September 2015. Geosciences, 9(9), 376.

Gonzalez, L. and Briottet, X. (2017) North Africa and Saudi Arabia day/night sandstorm survey (NASCube). Remote Sensing, 9(9), 896.

Guichard, F., Kergoat, L., Mougin, E., Timouk, F., Baup, F., Hiernaux, P. and Lavenu, F. (2009) Surface thermodynamics and radiative budget in the Sahelian Gourma: seasonal and diurnal cycles. Journal of Hydrology, 375(1-2), 161-177.

Guo, J., Xu, H., Liu, L., Chen, D., Peng, Y., Yim, S.H.L., Li, Y.Y.J., Zhao, C. and Zhai, P. (2019) The trend reversal of dust aerosol over East Asia and the North Pacific Ocean attributed to large-scale meteorology, deposition, and soil moisture. Journal of Geophysical Research: Atmospheres, 124(19), 10450-10466. https://doi.org/10.1029/2019JD030654.

Hastenrath, S. (1990) Decadal-scale changes of the circulation in the tropical Atlantic sector associated with Sahel drought. International Journal of Climatology, 10, 459-472.

Haywood, J. and Boucher, O. (2000) Estimates of the direct and indirect radiative forcing due to tropospheric aerosols: a review. Reviews of Geophysics, 38(4), 513-543.

Heald, C.L., Ridley, D.A., Kroll, J.H., Barrett, S.R.H., Cady-Pereira, K.E., Alvarado, M.J. and Holmes, C.D. (2014) Contrasting the direct radiative effect and direct radiative forcing of aerosols. Atmospheric Chemistry and Physics, 14(11), 5513-5527.

Hersbach, H., \& Dee, D.J.E.N. (2016). ERA5 reanalysis is in production. ECMWF newsletter, 147(7), 5-6.

Holben, B.N., Eck, T.F., Slutsker, I., Tanre, D., Buis, J.P., Setzer, A., Vermote, E., Reagan, J.A., Kaufman, Y.J., Nakajima, T., Lavenu, F., Jankowiak, I. and Smirnov, A. (1998) AERONET—A federated instrument network and data archive for aerosol characterization. Remote Sensing of Environment, 66(1), 1-16.

Hovmöller, E. (1949) The trough-and-ridge diagram. Tellus, 1(2), 62-66.

Hsu, N.C., Tsay, S.C., King, M.D. and Herman, J.R. (2004) Aerosol properties over bright-reflecting source regions. IEEE Transactions on Geoscience and Remote Sensing, 42(3), 557-569.

Jones, C., Mahowald, N. and Luo, C. (2004) Observational evidence of African desert dust intensification of easterly waves. Geophysical Research Letters, 31(17), L17208.

Klose, M., Shao, Y., Karremann, M.K. and Fink, A.H. (2010) Sahel dust zone and synoptic background. Geophysical Research Letters, 37(9), L09802.

Knippertz, P. (2008) Dust emissions in the West African heat trough - the role of the diurnal cycle and of extratropical disturbances. Meteorologische Zeitschrift, 17(5), 553-563.

Knippertz, P., Deutscher, C., Kandler, K., Müller, T., Schulz, O. and Schütz, L. (2007) Dust mobilization due to density currents in the Atlas region: observations from the Saharan Mineral Dust Experiment 2006 field campaign. Journal of Geophysical Research: Atmospheres, 112(D21), D21109.
Knippertz, P., Fink, A.H., Deroubaix, A., Morris, E., Tocquer, F., Evans, M.J., Flamant, C., Gaetani, M., Lavaysse, C., Mari, C., Marsham, J.H., Meynadier, R., Affo-Dogo, A., Bahaga, T., Brosse, F., Deetz, K., Guebsi, R., Latifou, I., Maranan, M., Rosenberg, P.D. and Schlueter, A. (2017) A meteorological and chemical overview of the DACCIWA field campaign in West Africa in June-July 2016. Atmospheric Chemistry and Physics, 17, 10893-10918. https://doi.org/10.5194/acp-17-108932017.

Knippertz, P. and Stuut, J.B.W. (2014) Mineral Dust: A Key Player in the Earth System. Dordrecht: Springer. https://doi.org/10.1007/ 978-94-017-8978-3.

Knippertz, P. and Todd, M.C. (2010) The central west Saharan dust hot spot and its relation to African easterly waves and extratropical disturbances. Journal of Geophysical Research: Atmospheres, 115(D12), D12117.

Kocha, C., Tulet, P., Lafore, J.P. and Flamant, C. (2013) The importance of the diurnal cycle of Aerosol Optical Depth in West Africa. Geophysical Research Letters, 40(4), 785-790.

Kylling, A., Vandenbussche, S., Capelle, V., Cuesta, J., Klüser, L., Lelli, L., Popp, T., Stebel, K. and Veefkind, P. (2018) Comparison of dust-layer heights from active and passive satellite sensors. Atmospheric Measurement Techniques, 11, 2911-2936. https:// doi.org/10.5194/amt-11-2911-2018.

Lafore, J.-P., Flamant, C., Guichard, F., Parker, D.J., Bouniol, D., Fink, A.H., Giraud, V., Gosset, M., Hall, N., Holler, H., Jones, S.C., Protat, A., Roca, R., Roux, F., Said, F. and Thorncroft, C. (2011) Progress in understanding of weather systems in West Africa. Atmospheric Science Letters, 12, 7-12. https://doi.org/10.1002/asl. 335.

Lavaysse, C., Flamant, C., Janicot, S. and Knippertz, P. (2010) Links between African easterly waves, midlatitude circulation and intraseasonal pulsations of the West African heat low. Quarterly Journal of the Royal Meteorological Society, 136(S1), 141-158.

Legrand, M., Dubovik, O., Lapyonok, T. and Derimian, Y. (2014) Accounting for particle non-sphericity in modeling of mineral dust radiative properties in the thermal infrared. Journal of Quantitative Spectroscopy \& Radiative Transfer, 149, 219-240.

Lélé, I.M. and Lamb, P.J. (2010) Variability of the intertropical front (ITF) and rainfall over the West African Sudan-Sahel zone. Journal of Climate, 23(14), 3984-4004.

Liu, L., Guo, J., Gong, H., Li, Z., Chen, W., Wu, R., Wang, L., Xu, H., Li, J., Chen, D. and Zhai, P. (2019) Contrasting influence of Gobi and Taklimakan deserts on the dust aerosols in western North America. Geophysical Research Letters, 46(15), 9064-9071. https://doi.org/10.1029/2019GL083508.

Lothon, M., Saïd, F., Lohou, F. and Campistron, B. (2008) Observation of the diurnal cycle in the low troposphere of West Africa. Monthly Weather Review, 136(9), 3477-3500.

Mahowald, N.M., Baker, A., Bergametti, G., Brooks, N., Duce, R., Jickells, T., Kubilay, N., Prospero, J. and Tegen, I. (2005) Atmospheric global dust cycle and iron inputs to the ocean. Global Biogeochemical Cycles, 19(4), GB4025. https://doi.org/10.1029/ 2004GB002402.

Mahowald, N.M., Ballentine, J.-A., Feddema, J. and Ramankutty, N. (2007) Global trends in visibility: implications for dust sources. Atmospheric Chemistry and Physics, 7, 3309-3337.

Mahowald, N.M., Kloster, S., Engelstaedter, S., Keith Moore, J., Mukhopadhyay, S., McConnell, J.R., Albani, S., Doney, S.C., Bhattacharya, A., Curran, M.A.J., Flanner, M.G., Hoffman, F.M., 
Lawrence, D.M., Lindsay, K., Mayewski, P.A., Neff, J., Rothenberg, D., Thomas, E., Thornton, P.E. and Zender, C.S. (2001) Observed 20th century desert dust variability: impact on climate and biogeochemistry. Atmospheric Chemistry and Physics, 10(22), 10875-10893.

Marsham, J.H., Parker, D.J., Grams, C.M., Taylor, C.M. and Haywood, J.M. (2008) Uplift of Saharan dust south of the intertropical discontinuity. Journal of Geophysical Research: Atmospheres, 113(D21), D21102. https://doi.org/10.1029/2008JD009844.

Meloni, D., Di Sarra, A., Di Iorio, T. and Fiocco, G. (2005) Influence of the vertical profile of Saharan dust on the visible direct radiative forcing. Journal of Quantitative Spectroscopy \& Radiative Transfer, 93(4), 397-413.

Newman, S.M., Smith, J.A., Glew, M.D., Rogers, S.M. and Taylor, J.P. (2005) Temperature and salinity dependence of sea surface emissivity in the thermal infrared. Quarterly Journal of the Royal Meteorological Society, 131(610), 2539-2557.

O'Neill, N.T., Eck, T.F., Smirnov, A., Holben, B.N. and Thulasiraman, S. (2003) Spectral discrimination of coarse and fine mode optical depth. Journal of Geophysical Research: Atmospheres, 108(D17), 4559.

Paul, M., Aires, F., Prigent, C., Trigo, I.F. and Bernardo, F. (2012) An innovative physical scheme to retrieve simultaneously surface temperature and emissivities using high spectral infrared observations from IASI. Journal of Geophysical Research: Atmospheres, 117(D11), D11302.

Pierangelo, C., Chédin, A. and Chazette, P. (2004) Measurements of stratospheric volcanic aerosol optical depth from NOAA TIROS Observational Vertical Sounder (TOVS) observations. Journal of Geophysical Research: Atmospheres, 109(D3), D03207.

Popp, T., de Leeuw, G., Bingen, C., Brühl, C., Capelle, V., Chedin, A., Clarisse, L., Dubovik, O., Grainger, R., Griesfeller, J., Heckel, A., Kinne, S., Klüser, L., Kosmale, M., Kolmonen, P., Lelli, L., Litvinov, P., Mei, L., North, P., Pinnock, S., Povey, A., Robert, C., Schulz, M., Sogacheva, L., Stebel, K., Stein Zweers, D., Thomas, G., Tilstra, L., Vandenbussche, S., Veefkind, P., Vountas, M. and Xue, Y. (2016) Development, production and evaluation of aerosol climate data records from European satellite observations (Aerosol_cci). Remote Sensing, 8, 1-34. https://doi.org/10.3390/ rs8050421.

Prospero, J.M. (1999) Assessing the impact of advected African dust on air quality and health in the eastern United States. Human and Ecological Risk Assessment, 5(3), 471-479.

Remer, L.A., Kaufman, Y.J., Tanré, D., Mattoo, S., Chu, D.A., Martins, J.V., Li, R.-R., Ichoku, C., Levy, R.C., Kleidman, R.G., Eck, T.F., Vermote, E. and Holben, B.N. (2005) The MODIS aerosol algorithm, products, and validation. Journal of the Atmospheric Sciences, 62(4), 947-973.

Roberts, A. and Knippertz, P. (2012) Haboobs: convectively generated dust storms in West Africa. Weather, 67(12), 311-316.

Roberts, A.J. and Knippertz, P. (2014) The formation of a large summertime Saharan dust plume: convective and synoptic-scale analysis. Journal of Geophysical Research: Atmospheres, 119(4), 1766-1785.

Rodgers, C.D. (2000) Inverse Methods for Atmospheric Sounding: Theory and Practice. London: World Scientific Publishing Company.

Ryder, C.L., Highwood, E.J., Rosenberg, P.D., Trembath, J., Brooke, J.K., Bart, M., Dean, A., Crosier, J., Dorsey, J., Brindley, H., Banks,
J., Marsham, J.H., McQuaid, J.B., Sodemann, H. and Washington, R. (2013) Optical properties of Saharan dust aerosol and contribution from the coarse mode as measured during the Fennec 2011 aircraft campaign. Atmospheric Chemistry and Physics, 13, 303-325. https://doi.org/10.5194/acp-13-3032013.

Sayer, A.M., Hsu, N.C., Bettenhausen, C. and Jeong, M.-J. (2013) Validation and uncertainty estimates for MODIS Collection 6 "Deep Blue" aerosol data. Journal of Geophysical Research: Atmospheres, 14, 7864-7872.

Schepanski, K., Tegen, I., Laurent, B., Heinold, B. and Macke, A. (2007) A new Saharan dust source activation frequency map derived from MSG-SEVIRI IR-channels. Geophysical Research Letters, 34(18), L18803.

Stiller, G.P. (Ed.) with contributions from v. Clarmann, T., Dudhia, A., Echle, G., Funke, B., Glatthor, N., Hase, F., Höpfner, M., Kellmann, S., Kemnitzer, H., Kuntz, M., Linden, A., Linder, M., Stiller, G. P., and Zorn, S.: The Karlsruhe Optimized and Precise Radiative Transfer Algorithm (KOPRA), vol. FZKA 6487 of Wissenschaftliche Berichte, Forschungszentrum Karlsruhe, Germany, 2000.

Su, X., Goloub, P., Chiapello, I., Chen, H., Ducos, F. and Li, Z. (2010) Aerosol variability over East Asia as seen by POLDER space-borne sensors. Journal of Geophysical Research: Atmospheres, 115(D24), D24215.

Sultan, B. and Janicot, S. (2000) Abrupt shift of the ITCZ over West Africa and intra-seasonal variability. Geophysical Research Letters, 27, 3353-3356.

Sultan, B. and Janicot, S. (2003) The West African monsoon dynamics. Part II: the 'preonset' and 'onset' of the summer monsoon. Journal of Climate, 16, 3407-3427.

Tikhonov, A. (1963) On the solution of incorrectly stated problems and a method of regularization. Doklady Akademii Nauk SSSR, 151, 501-504.

Torres, O., Tanskanen, A., Veihelmann, B., Ahn, C., Braak, R., Bhartia, P.K., Veefkind, P. and Levelt, P. (2007) Aerosols and surface UV products from Ozone Monitoring Instrument observations: an overview. Journal of Geophysical Research: Atmospheres, 112(D24), D24S47.

Vandenbussche, S., Kochenova, S., Vandaele, A.C., Kumps, N. and De Mazière, M. (2013) Retrieval of desert dust aerosol vertical profiles from IASI measurements in the TIR atmospheric window. Atmospheric Measurement Techniques, 6, 2577-2591. https://doi. org/10.5194/amt-6-2577-2013.

Washington, R., Flamant, C., Parker, D.J., Marsham, J., McQuaid, J.B., Brindley, H., Todd, M., Highwood, E.J., Chaboureau, J.-P., Kocha, C., Bechir, M., Saci, A. and Ryder, C.L. (2012) Fennec - The Saharan Climate System, CLIVAR Exchanges No. 60. Southampton: International CLIVAR Project Office, pp. 31-32.

Washington, R. and Todd, M.C. (2005) Atmospheric controls on mineral dust emission from the Bodélé Depression, Chad: the role of the low level jet. Geophysical Research Letters, 32(17), L17701.

Winker, D.M., Hunt, W.H. and McGill, M.J. (2007) Initial performance assessment of CALIOP. Geophysical Research Letters, 34, L19803. https://doi.org/10.1029/2007GL030135.

Winker, D.M., Vaughan, M.A., Omar, A., Hu, Y., Powell, K.A., Liu, Z., Hunt, W.H. and Young, S.A. (2009) Overview of the CALIPSO mission and CALIOP data processing algorithms. Journal of Atmosphere Oceanic Technology, 26(11), 2310-2323. 
Xu, X., Gao, J., Gao, J. and Chen, Y. (1994) Air pollution and daily mortality in residential areas of Beijing, China. Archives of Environmental Health, 49(4), 216-222.

Yoshioka, M., Mahowald, N., Conley, A., Collins, W., Fillmore, D., Zender, C. and Coleman, D. (2007) Impact of desert dust radiative forcing on Sahel precipitation: relative importance of dust compared to sea surface temperature variations, vegetation changes and greenhouse gas warming. Journal of Climate, 20, 1445-1467. https://doi.org/10.1175/JCLI4056.1.

Young, S., Winker, D., Vaughan, M., Hu, Y and Kuehn, R. (2008) CALIOP Algorithm Theoretical Basis Document Part 4: Extinction Retrieval Algorithms. Available at: http://wwwcalipso.larc.nasa.gov/resources/pdfs/PC-SCI-202_Part4_v1.0. pdf [Accessed 15 June 2020].
Yu, H., Remer, L.A., Chin, M., Bian, H., Tan, Q., Yuan, T. and Zhang, Y. (2012) Aerosols from overseas rival domestic emissions over North America. Science, 337(6094), 566-569. https://doi.org/10. 1126/science.1217576.

How to cite this article: Cuesta J, Flamant C, Gaetani M, et al. Three-dimensional pathways of dust over the Sahara during summer 2011 as revealed by new Infrared Atmospheric Sounding Interferometer observations . Q J R Meteorol Soc. 2020;146:2731-2755. https://doi.org/10.1002/qj. 3814 